\title{
Acoustical performance of winter tyres on in-service road surfaces
}

\author{
Tiago Vieira ${ }^{\mathrm{a}, \mathrm{b}, *}$, Ulf Sandberg ${ }^{\mathrm{a}}$, Sigurdur Erlingsson ${ }^{\mathrm{a}, \mathrm{b}, \mathrm{c}}$ \\ ${ }^{a}$ Swedish National Road and Transport Research Institute (VTI), Olaus Magnus vaeg, 35, 58330 Linkoeping, Sweden \\ ${ }^{\mathrm{b}}$ Department of Building Materials, Brinellvaegen, 23, KTH Royal Institute of Technology, SE 10044 Stockholm, Sweden \\ ${ }^{\mathrm{c}}$ Faculty of Civil \& Environmental Engineering, University of Iceland, IS 108 Reykjavik, Iceland
}

\section{A R T I C L E I N F O}

\section{Article history:}

Received 7 December 2018

Received in revised form 25 February 2019

Accepted 24 March 2019

\section{Keywords:}

Pavement

Tyre

Noise

Studs

Winter

$\mathrm{M}+\mathrm{S}$

\begin{abstract}
A B S T R A C T
Exposure to excessively high noise levels is a relevant health problem in Europe and road traffic noise is the most widespread noise source. When considering cold climate countries, the available scientific literature on noise emission properties of winter tyres is still very limited. In order to contribute into filling this knowledge gap, this paper investigates the acoustical performance of different types of tyres, with focus on winter tyres, on different road surfaces, at different speeds, and with different states of wear. The results indicate that studded winter tyres have, indeed, an increased noise level at frequencies between $315 \mathrm{~Hz}$ and $10 \mathrm{kHz}$, having a significantly different response especially at frequencies higher than $4 \mathrm{kHz}$. The acoustical response also depends on the tyre type when comparing different road surfaces, as a result of conflicting vibrational and aerodynamic noise generation mechanisms. Additionally, the relationship between labelled and measured values was explored, however, no statistically significant relationship was found between them (and labelling is not applied for studded tyres). A frequency spectrum correction was attempted based on previous measurements on an ISO track, which reduced the difference between measured and labelled values, however, further investigation is still required to properly understand differences between label and road measurements, where the label is determined on a test track with a special, smooth surface.
\end{abstract}

(c) 2019 Elsevier Ltd. All rights reserved.

\section{Introduction}

Exposure to excessive noise levels has a serious impact on public health, as illustrated by the fact that more than 125 million people in the European Union are exposed to road traffic noise levels above $55 \mathrm{~dB} \mathrm{~L}_{\mathrm{den}}$ and more than 37 millions exposed to levels above $65 \mathrm{~dB} \mathrm{~L}_{\mathrm{den}}$ [1]. Moreover, road traffic noise is the most widespread noise source in the European Union. According to an estimate from the World Health Organization, as a result of excessive exposure to traffic-related noise, approximately one million life years are lost every year in the western part of Europe [2]. Another research [3] also confirmed that traffic noise is a relevant health issue by evaluating data from selected European countries.

In northern countries with severe winter climates, such as Sweden, Norway, Finland, Iceland, Russia, Canada and some states in the USA, studs mounted in the tyre tread are used in order to provide the best possible friction on icy roads. These studs, that may

* Corresponding author at: Swedish National Road and Transport Research Institute (VTI), Olaus Magnus vaeg, 35, 58330 Linkoeping, Sweden.

E-mail addresses: tiago.vieira@vti.se (T. Vieira), ulf.sandberg@vti.se (U. Sandberg), sigurdur.erlingsson@vti.se (S. Erlingsson). amount to 80-200 per tyre, have the disadvantages that they dramatically increase the wear on the road surface and subsequent spread of fine particles in the air, and also that they increase noise emission. Consequently, the safety benefits are compromised by environmental, health and economic effects, which makes the acceptance of studded winter tyres arguable and often questioned by authorities and environmental interest groups.

Until recently, it has been a general view that tyres for winter service are noisier than regular ("summer") passenger car tyres; this being applicable to both interior and exterior noise emission. In some cases in the past decades, this could be backed by test results measured on smooth-textured surfaces [4]. The reason was that in order to provide good traction and friction during winter conditions; especially in snow and slush, tyres were designed with a high air/rubber ratio in the tread pattern, which mostly meant that tread patterns contained relatively large blocks with relatively wide grooves in-between. Rubber compounds were far from today's quality. The technical progress, however, has been very successful with respect not the least to winter tyres, and today's winter tyres are made with very advanced, modern, soft rubber compounds, and they no longer have large solid blocks; instead they have tread elements which are cut by sipes into rows 
Table 1

Tested tyre categories, designations, descriptions and the respective number of samples.

\begin{tabular}{|c|c|c|c|}
\hline Tyre Category & Designation & Description & Number of samples \\
\hline All-season & AS & A compromise between summer and winter tyres & 4 \\
\hline Summer & SU & Tyres used in summer conditions only & 8 \\
\hline Winter & WI & Tyres with no studs nor hard particles in the tyre tread & 24 \\
\hline Winter - Green Diamond & WIGD & Tyres with hard particles in the tyre tread & 2 \\
\hline Winter - Studded & WIST & Tyres with studs in the tyre tread & 12 \\
\hline
\end{tabular}

Table 2

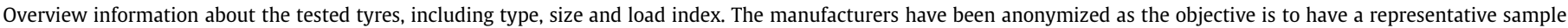
and not to compare different manufacturers.

\begin{tabular}{|c|c|c|c|c|c|c|c|}
\hline Tyre Number & Type & Manufacturer & SIZE & Tyre Number & Type & Manufacturer & SIZE \\
\hline 1 & AS & M3 & 195/60R15 & 26 & WI & M8 & 195/60R15 \\
\hline 2 & AS & M11 & 195/60R15 & 27 & WI & M8 & 195/60R15 \\
\hline 3 & AS & M5 & 195/60R15 & 28 & WI & M4 & 185/60R15 \\
\hline 4 & AS & M4 & 195/60R15 & 29 & WI & M2 & 195/60R15 \\
\hline 5 & SU & M13 & $195 / 65 R 15$ & 30 & WI & M2 & 195/60R15 \\
\hline 6 & SU & M13 & $195 / 65 R 15$ & 31 & WI & M2 & $205 / 55 R 16$ \\
\hline 7 & SU & M13 & $195 / 65 R 15$ & 32 & WI & M10 & 205/55R16 \\
\hline 8 & SU & M4 & 195/60R15 & 33 & WI & M2 & 205/55R16 \\
\hline 9 & SU & M4 & 195/60R15 & 34 & WI & M2 & 205/55R16 \\
\hline 10 & SU & M9 & 195/60R15 & 35 & WI & M2 & $205 / 55 R 16$ \\
\hline 11 & SU & M10 & 205/55R16 & 36 & WI & M10 & 205/55R16 \\
\hline 12 & SU & M10 & 195/60R15 & 37 & WIGD & M15 & $185 / 65 R 15$ \\
\hline 13 & WI & M12 & 195/60R15 & 38 & WIGD & M15 & 185/65R15 \\
\hline 14 & WI & M10 & 195/60R15 & 39 & WIST & M14 & 185/65R15 \\
\hline 15 & WI & M10 & 195/60R15 & 40 & WIST & M16 & 185/65R15 \\
\hline 16 & WI & M6 & 195/60R15 & 41 & WIST & M16 & $185 / 65 R 15$ \\
\hline 17 & WI & M6 & 195/60R15 & 42 & WIST & M7 & 185/60R15 \\
\hline 18 & WI & M4 & 195/60R15 & 43 & WIST & M7 & 185/60R15 \\
\hline 19 & WI & M4 & 195/60R15 & 44 & WIST & M1 & 185/65R15 \\
\hline 20 & WI & $\mathrm{M} 2$ & 195/60R15 & 45 & WIST & M2 & 195/60R15 \\
\hline 21 & WI & M14 & 185/60R16 & 46 & WIST & M2 & 195/60R15 \\
\hline 22 & WI & M14 & 185/60R15 & 47 & WIST & M4 & 185/65R15 \\
\hline 23 & WI & M2 & 185/65R15 & 48 & WIST & M9 & 185/65R15 \\
\hline 24 & WI & $\mathrm{M} 2$ & $185 / 65 R 15$ & 49 & WIST & M2 & 195/60R15 \\
\hline 25 & WI & M9 & $195 / 65 R 15$ & 50 & WIST & M2 & 195/60R15 \\
\hline
\end{tabular}

Table 3

Tested pavement surfaces and the respective MPD values.

\begin{tabular}{lll}
\hline $\begin{array}{l}\text { Pavement type in European } \\
\text { terminology }\end{array}$ & $\begin{array}{l}\text { Corresponding Swedish } \\
\text { pavement type }\end{array}$ & $\begin{array}{l}\text { Average MPD } \\
{[\mathrm{mm}]}\end{array}$ \\
\hline SMA 8 (proxy for ISO 10844) & ABS 8 & 0.78 \\
DAC 16 ( SMA 16) & ABS 16 & 1.09 \\
\hline
\end{tabular}

Table 4

Descriptive statistics for the different tyre groups. Note that each measurement point corresponds to an average for all the repetitions on the two different pavements and test speeds.

\begin{tabular}{llllll}
\hline & AS & SU & WI & WIGD & WIST \\
\hline Count & 24 & 48 & 144 & 12 & 72 \\
Mean & 89.6 & 90.1 & 89.5 & 87.9 & 97.2 \\
Standard Deviation & 6.6 & 6.4 & 6.5 & 6.0 & 5.4 \\
Minimum & 79.7 & 79.6 & 77.9 & 80.1 & 86.7 \\
$25 \%(Q 1)$ & 82.7 & 83.0 & 82.1 & 81.2 & 93.3 \\
$50 \%(Q 2)$ & 90.3 & 90.3 & 89.6 & 88.2 & 97.6 \\
$75 \%(Q 3)$ & 95.9 & 96.9 & 96.0 & 94.4 & 101.3 \\
Maximum & 99.2 & 99.9 & 101.3 & 95.1 & 106.6 \\
\hline
\end{tabular}

of rather narrow "ridges". This makes such tread patterns very flexible. Wide grooves only exist in the longitudinal direction. A comprehensive review of how different tyre parameters affect the resulting noise and how the tyre design has changed over time can be found in Gent and Walter [5] or Sandberg and Ejsmont [4].

Noise generation for summer tyres has been studied and documented as they are the most common type of tyres [6]. However, the published knowledge about noise emission from winter tyres is, despite the recent developments in tyre design, still limited. Not many scientific publications on winter tyres are available, and when considering studded tyres, there is even less information available. This is most probably because testing studded tyres poses special operational difficulties, for instance, testing studded tyres on a drum would damage the drum equipment itself. Since such tyres are allowed only in a few regions in the world, the available literature is indeed limited. Here we purposely neglect the extensive annual test results for winter tyres published by motor magazines or newspapers, since they are not scientifically conducted and reported.

The first comprehensive testing of winter tyres was made in a VTI/TUG project run in 1995-2000, in which approximately 100 car tyres of rather similar dimensions were tested for noise, rolling resistance and wet friction properties [4,7]. The test program included 41 winter tyres, of which 7 were studded, compared to approximately 60 "summer tyres". The noise emissions were measured with an early version of the CPX (Close Proximity) method, nowadays specified in ISO 11819-2 [8]. The results for noise can be summarized as follows, as tested on a dense asphalt concrete (DAC) with $16 \mathrm{~mm}$ maximum aggregate size. With the summer tyres as a reference, the winter tyres were on the average $0.9 \mathrm{~dB}$ 
(A-weighted) quieter, while the studded winter tyres were $2.3 \mathrm{~dB}$ noisier. At the same time, a German study was conducted, including 37 winter and all seasons tyres (no studded tyres) compared to 35 summer tyres [9]. The results were grouped into different dimensions and showed that for some dimensions winter tyres were up to $1 \mathrm{~dB}$ quieter than summer tyres, while it was the opposite for other dimensions. One should note that these tyres were of a design typical of the market tyres in the 1990's and are not necessarily representative of today's tyres. Another study was made by VTI in 2011/12. This only compared noise and friction properties of 10 tyres [10]. The noise measurements were performed on a standard surface in accordance to ISO 10,844 [11] and measured with the coast-by method [12]. The results indicated that the Aweighted levels of the winter tyres were quieter than the reference summer tyres and the winter tyres optimized for the northern European climate were quieter than the ones optimized for the central European climate.

In this study the CPX method has been applied to evaluate the noise emissions under different conditions. This method correlates well to other measurement methods; for instance, the Statistical Pass-By (SPB) method [13], and the Coast-By method [14]. One positive aspect of using the CPX method, however, is to analyse the acoustical results near the generating source, i.e. near the contact between the tyre and the pavement surface. This means that other disturbing factors like reflections and absorptions from the surroundings and contribution from other vehicles are minimized. Different measurement techniques for noise generated by the contact between the tyre and the road have been analysed in a recent state-of-the-art review by Li [15].

According to [4] there are 16 different mechanisms related to tyre/pavement noise, 9 of which are generation mechanisms and 7 are amplification mechanism. The surface texture, for instance, is responsible for exciting vibrations in the tyre structure and also provides gaps between the pavement and the tyre which may contribute to or reduce aerodynamic related mechanisms; often referred to as air pumping. A complete review of the different generation and amplification mechanisms is, however, out of the scope of this text.

The objective of this study was to analyse and evaluate how different tyres have different acoustical behaviour on different road surfaces, at different test speeds, and different states of wear. Special focus is laid on winter tyres, optimized for different climates and both with and without studs. Additional comments were made regarding the labelled values in comparison to the measured CPX values on in-service road surfaces. Different tyre categories were analysed, including all season tyres (AS), summer tyres (SU), winter tyres without studs (WI), winter tyres with studs (WIST) and winter tyres with hard particles (WIGD). The results of more than 600 measurements were analysed to provide a comprehensive analysis of the different acoustical behaviour of the different tested tyres under different test conditions.

\section{Measurement methods and measured tyres}

A total of 50 different tyres were tested regarding tyre/road noise on two different test sections and three different test speeds. For each tyre, test section and speed, a minimum of two and up to four runs were carried out, leading to more than 600 noise measurements in order to characterize how the acoustical performance of different tyres differ. The measurements were performed in two measurement campaigns, the first was between February and April of 2015 and the second was between March and April of 2016.

In addition, the road surface texture was evaluated, as well as rolling resistance properties of the same tyres. The latter is not reported in this text due to scope limitations; yet rolling resistance performance will be published in another article by the same authors.

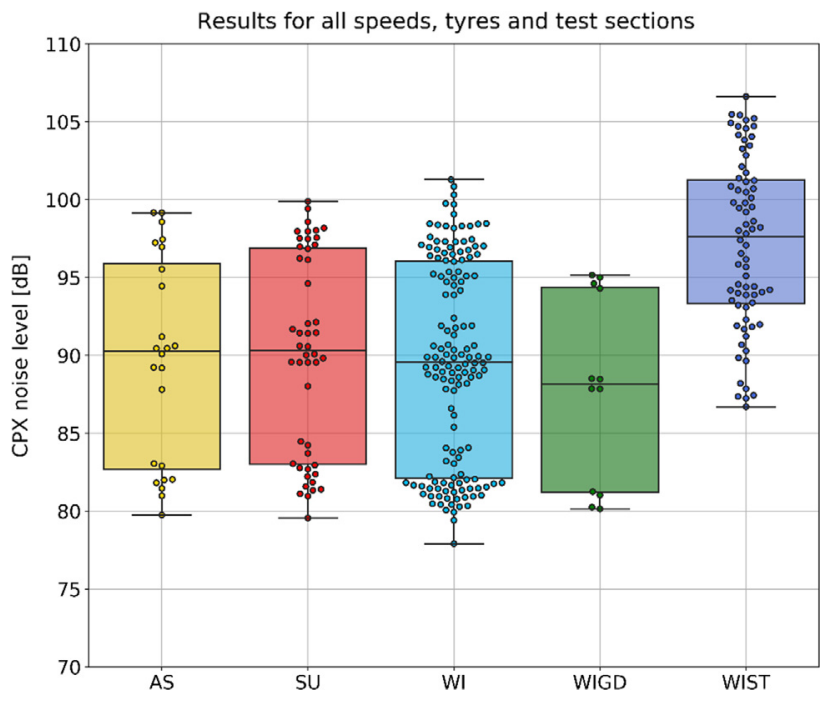

Fig. 2. Boxplot indicating the distribution of noise levels for all tyres, test tracks and speeds. The boxes include the median value for each category, the quartiles as the upper and lower limits for each box, and the minimum and maximum results as the whiskers upper and lower limits.

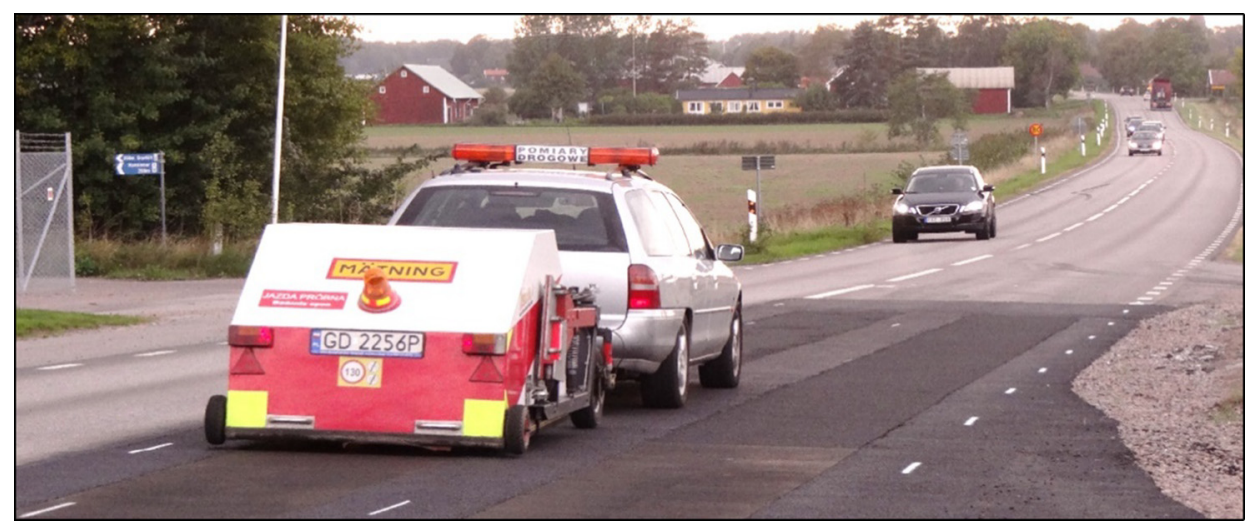

Fig. 1. The CPX trailer by TUG in operation in Sweden. 


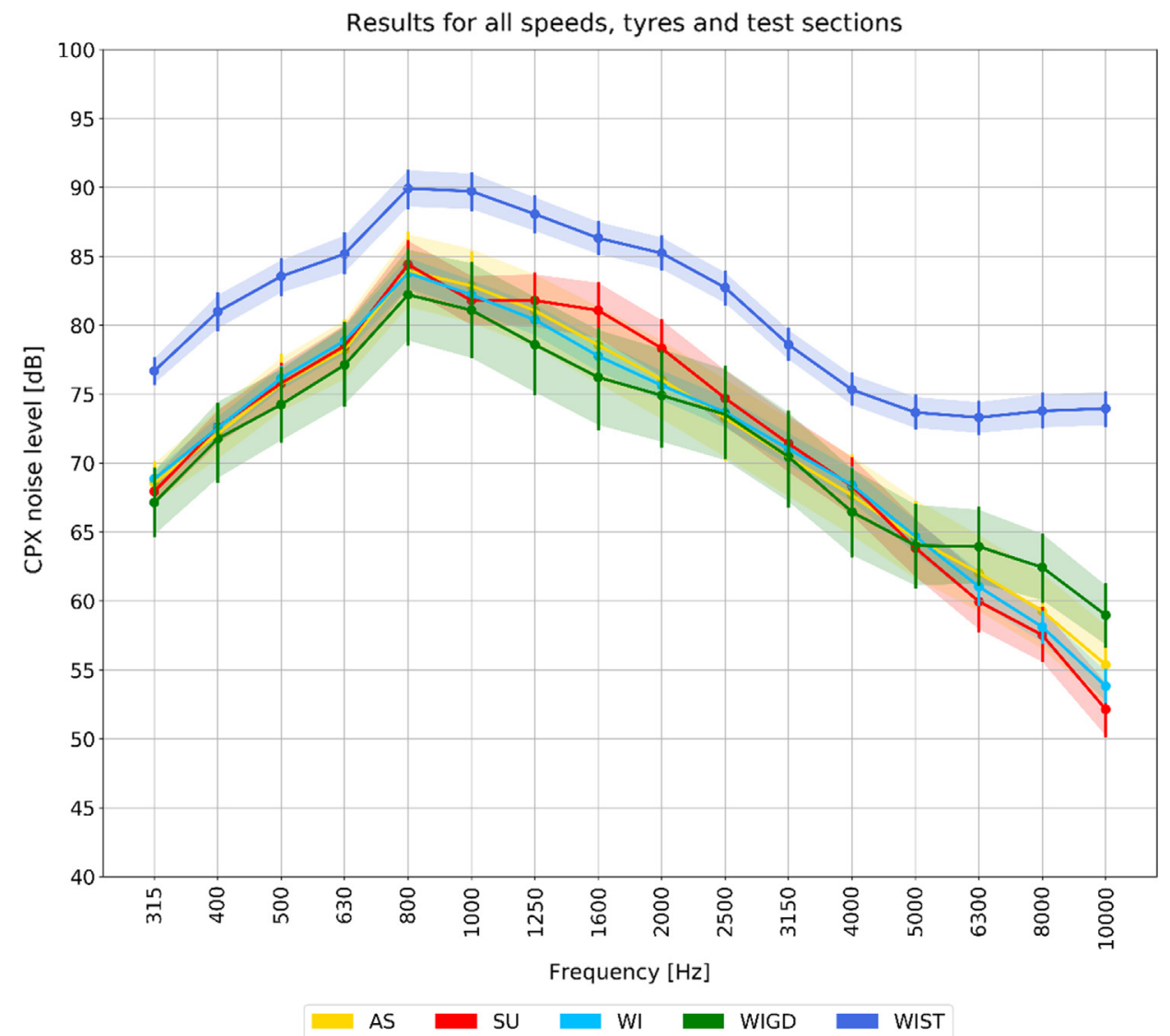

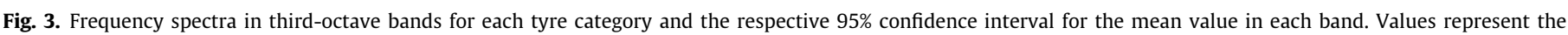
average for the two test sections and three test speeds.
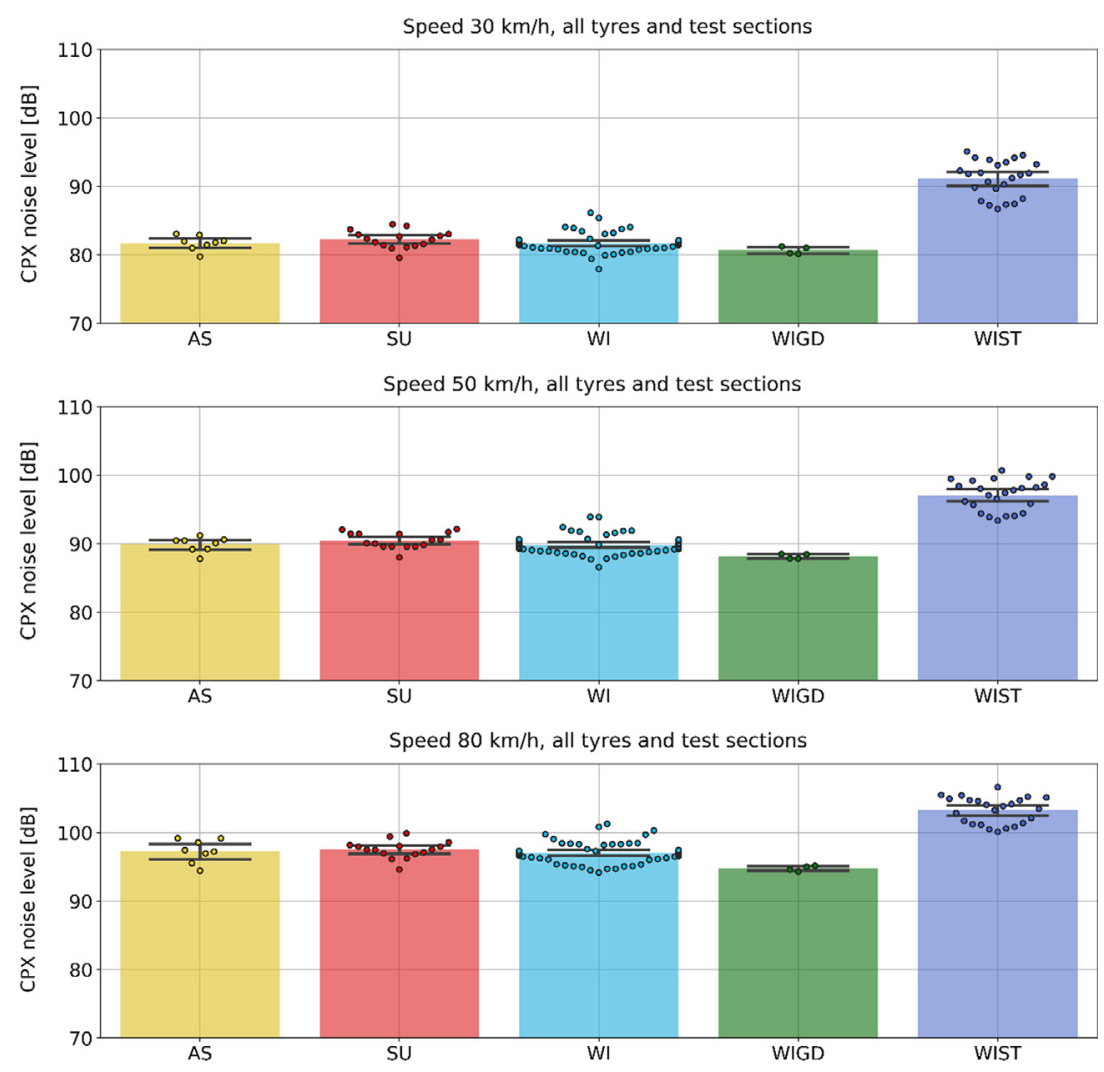

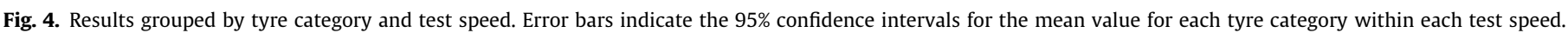




\subsection{Tested tyres}

There are essentially three different types of winter tyres for passenger cars: winter tyres optimized for central-European or similar climates, winter tyres optimized for north-European or similar climates and studded winter tyres. In this text, they are referred to as "European winter tyres", "Nordic winter tyres" and "studded winter tyres", respectively. The latter are generally used only in northern winter climates. Additionally, there is a tyre category called "all-season", which is a compromise between the common summer tyres and winter tyres design. Furthermore, there is a special winter tyre design which is essentially optimized for northern climates but has silicium carbide granules evenly mixed into the rubber compound of the tyre tread. This is intended to provide a frictional performance somewhat similar to that of studded tyres. Such tyres were also tested in this project, they were developed in Iceland using retreaded tyres and are marketed in the Nordic countries as well as in North America. In this paper they are referred to as "Green Diamond" tyres, referring to their brand name. The different tyre categories presented in this text, as well as the respective designations used further in this text, are presented in Table 1. As the objective is not to compare different tyre manufacturers nor specific models, such information is provided here for informative purposes only (Table 2).

The winter tyres without studs (WI) are further divided into central European and Nordic in this text due to the different optimization for different operational climates, as previously mentioned in this section. The summer tyres tested here were used as reference, as well as the reference tyre SRTT, the standard reference tyre according to ASTM 2493:14 [16].

The tyres named here were all tested in new condition, yet after a run-in process of $100 \mathrm{~km}$ and a warm-up process of about $15 \mathrm{~min}$ prior to each measurement. A small sample of 4 tyres was tested in both new and used conditions as well. The used conditions correspond to the average use for 2 winter seasons, and therefore, resulted in both chemical and mechanical ageing of the tested tyres.

\subsection{Tyre load and inflation pressure}

The tested tyres were loaded in accordance with ECE regulation R117 [17] leading to a load of $408 \mathrm{~kg}$ for the noise measurements. Inflation pressure was also adjusted in accordance with the specifications in ECE R117 leading to $180 \mathrm{kPa}$. An exception was the

Results for all tyres and test tracks
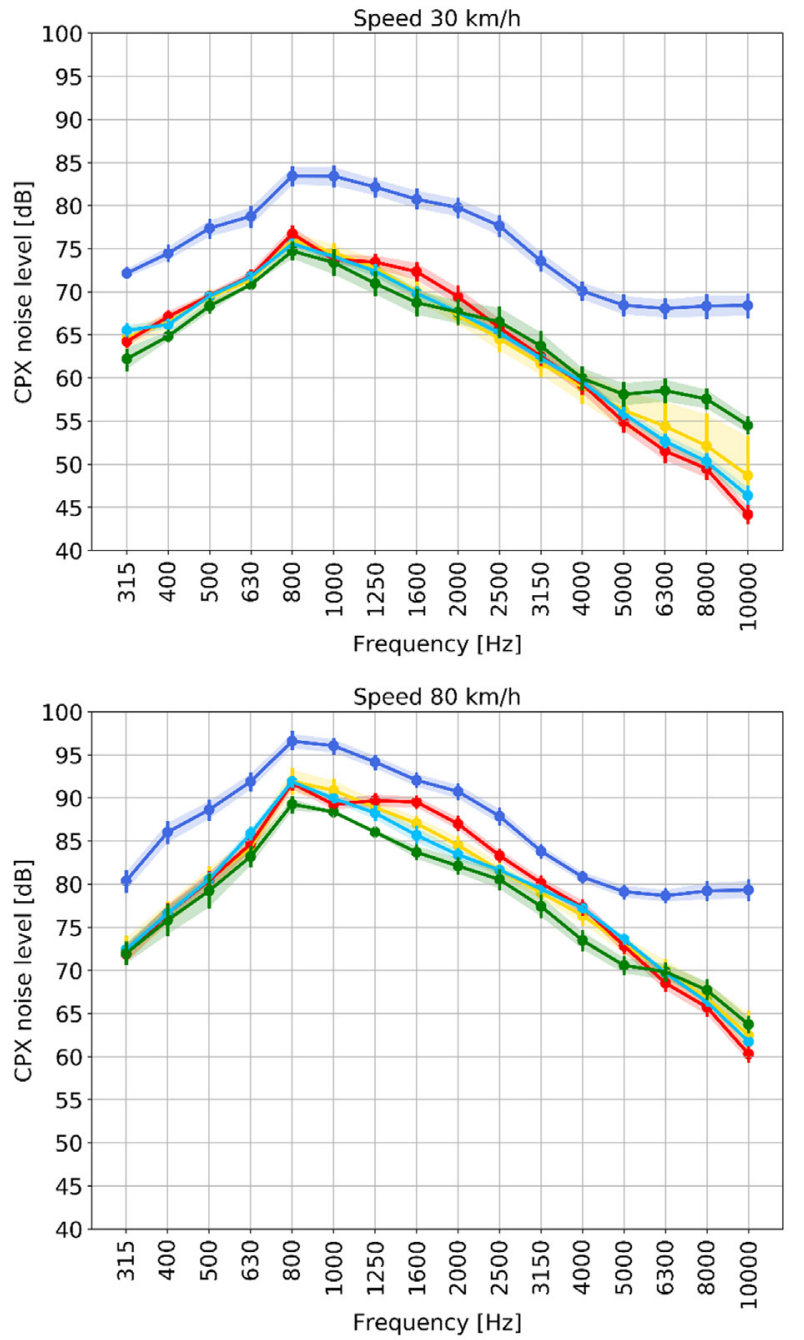

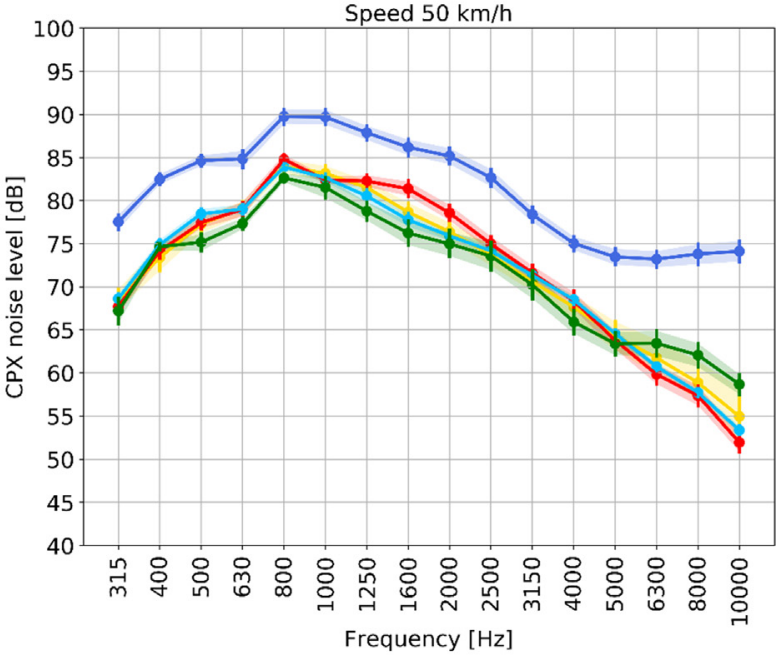

Frequency $[\mathrm{Hz}]$

$$
\square \text { AS SU WI W WIST WIST }
$$

Fig. 5. Frequency spectra in third-octave bands for each speed and tyre category including the $95 \%$ confidence interval for each band. 


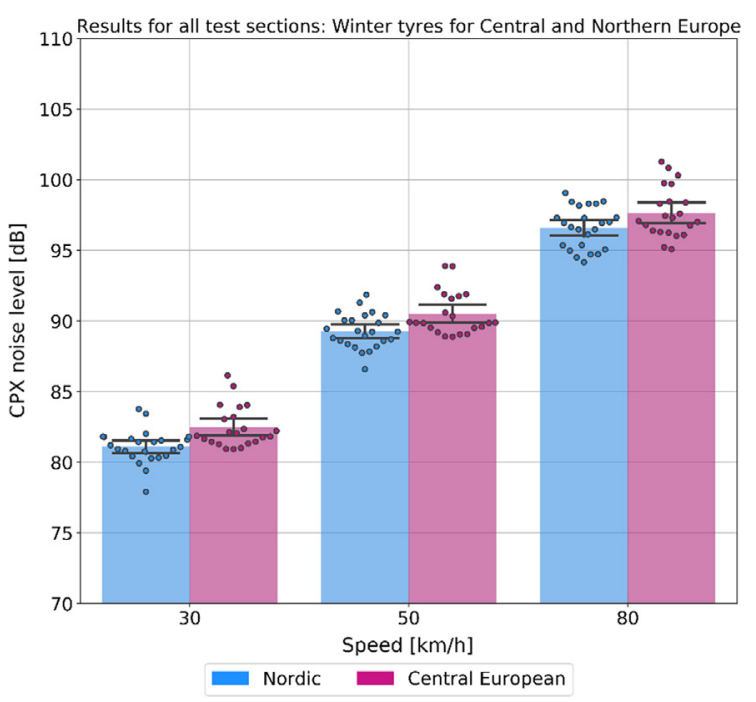

Fig. 6. Noise levels for winter tyres optimized for northern and central European conditions. Error bars indicate the $95 \%$ confidence interval for the mean value within each category and test speed.

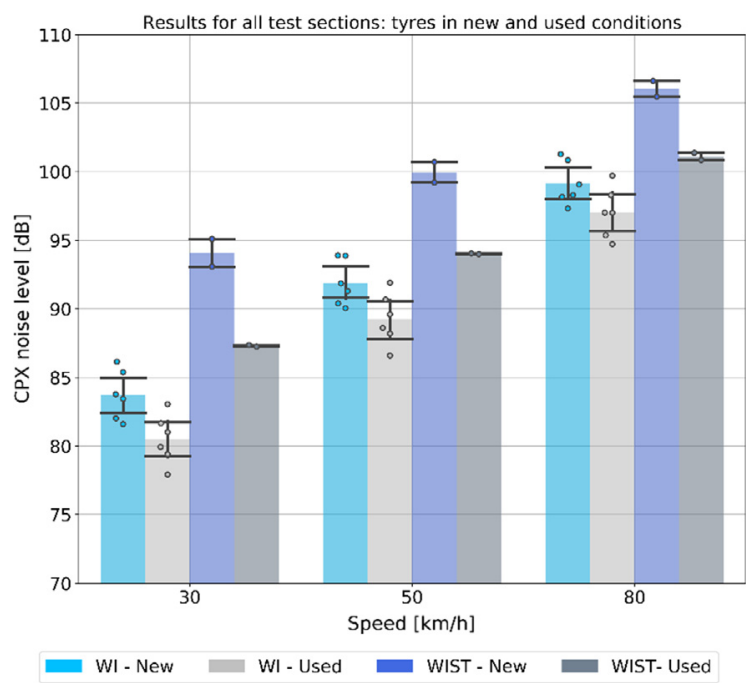

Fig. 8. Noise levels for WI and WIST tyres tested both in new and used conditions, and their respective 95\% confidence interval. Note that the sample size for this comparison is small.
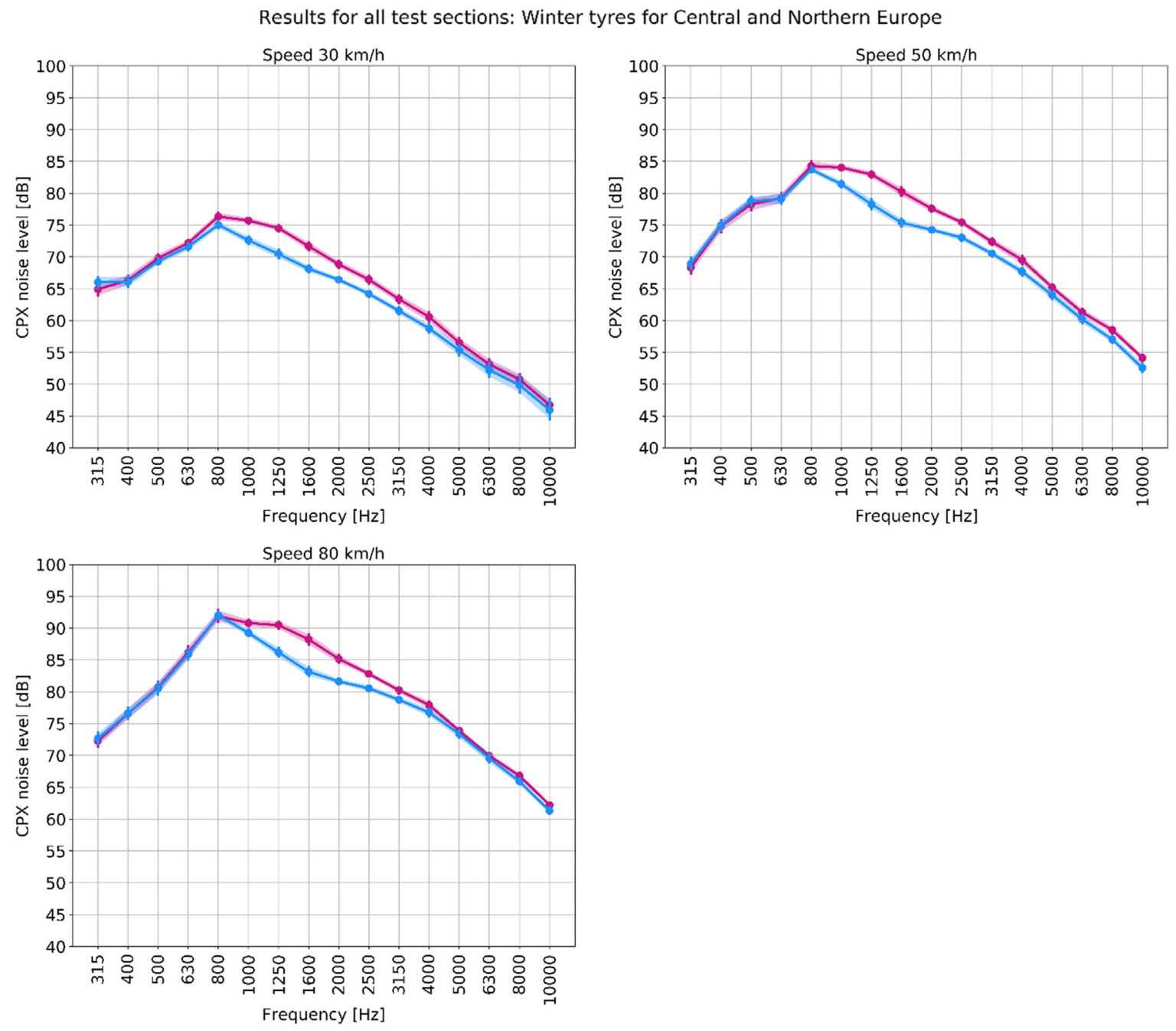

WI - Central Europe

WI - Northern Europe

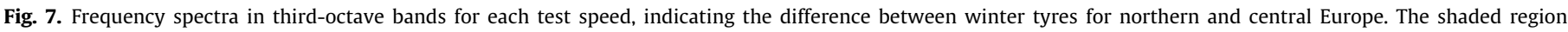
indicates the $95 \%$ confidence intervals for each band. 
SRTT (Standard Reference Test Tyre); a much larger tyre, yet it was tested with similar load and inflation as the other tyres. The reason was that the SRTT served only as a control tyre during each day of rolling resistance measurements, to check that there was no drift in results from day to day, apart from that corresponding to varying temperature.

Air, road and tyre surface temperatures were measured simultaneously with the noise and rolling resistance measurements. They were similar to typical Swedish late winter and early spring daytime temperatures in middle and southern parts of the country.

\subsection{Tested road surfaces}

Two road surfaces were used to evaluate the different tyre performances. One of the surfaces was a so-called DAC 16 (Dense Asphalt Concrete with maximum aggregate size $16 \mathrm{~mm}$ ) on an in-service road near Gdansk, in Poland. This surface was selected as its texture was similar to the SMA 16 road surface, which is the dominating surface on Swedish highways. The other surface is an SMA 8 (Stone Mastic Asphalt with maximum aggregate size $8 \mathrm{~mm}$ ), also on an in-service road near Gdansk, in Poland. Although somewhat rougher than a majority of ISO surfaces at the time of labelling, this surface was selected in order to serve as a proxy for the surface used when testing tyres according to EU regulations on tyre noise limits and noise labelling [11]. When these tyres were labelled (latest in 2014), the Regulation R117 still required the use of the old ISO surface specification (from 1994), when mean texture depth was required to be greater than $0.40 \mathrm{~mm}$ but with no restrictions for maximum texture. Some ISO surfaces then had texture depth in this range. Tyre ranking based on noise levels may be somewhat different on an ISO surface having an MPD or mean texture depth of (say) $0.44 \mathrm{~mm}$ and as in our (proxy) case having an MPD of $0.78 \mathrm{~mm}$, but this only reflects the problem with variation between ISO surfaces at the time when labelling measurements were conducted.

Both surfaces had their textures characterized by the Mean Profile Depth (MPD) in accordance with ISO 13473-1 [18]. The surface characterization was performed by VTI's Road Surface Texture measurement vehicle, in June 2015 [19]. The results are presented

Results for all test sections: tyres in new and used conditions
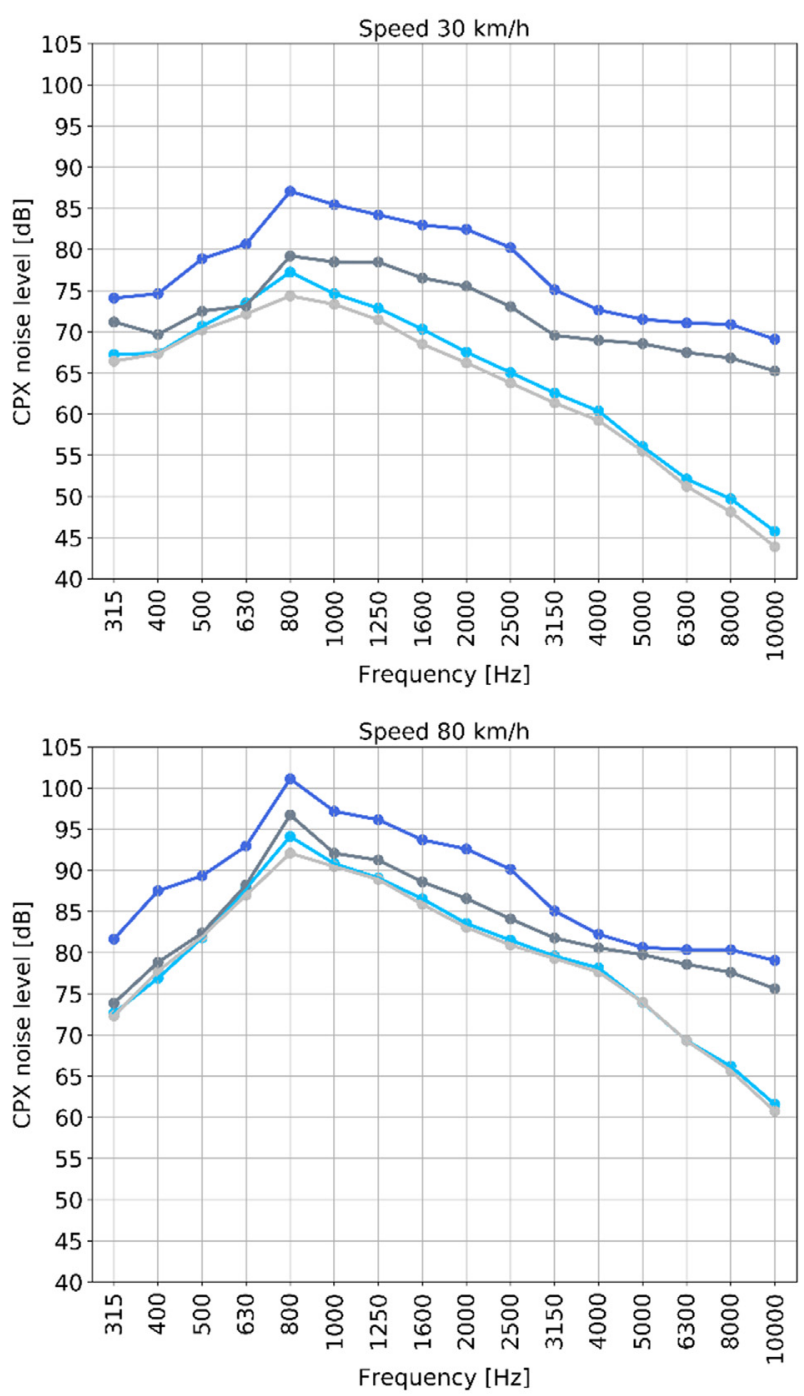

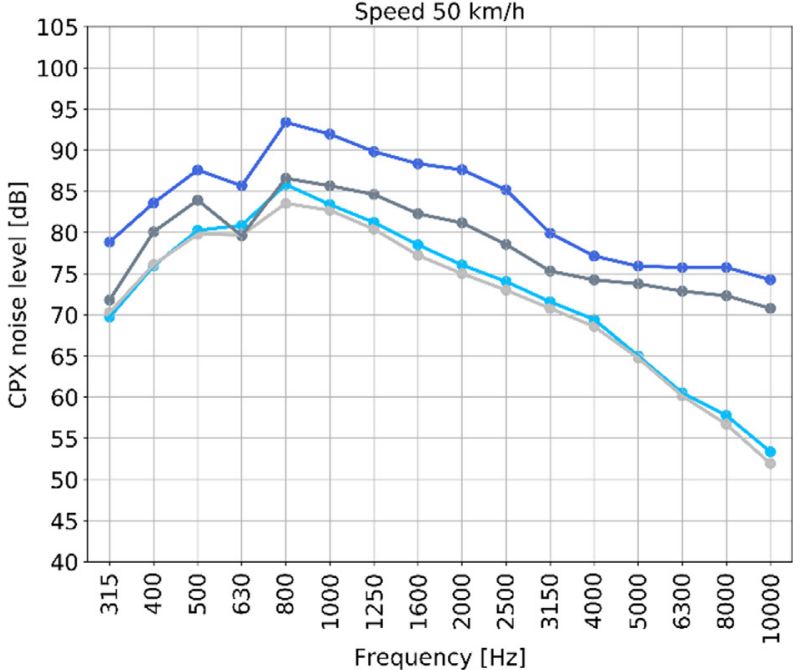

Frequency $[\mathrm{Hz}]$

WI-NEW WI-Used

WIST - NeW

WIST - Used

Fig. 9. Frequency spectra for WI and WIST tyres tested both in new and used conditions and their respective standard deviation. Note that the sample size for this comparison is small. 


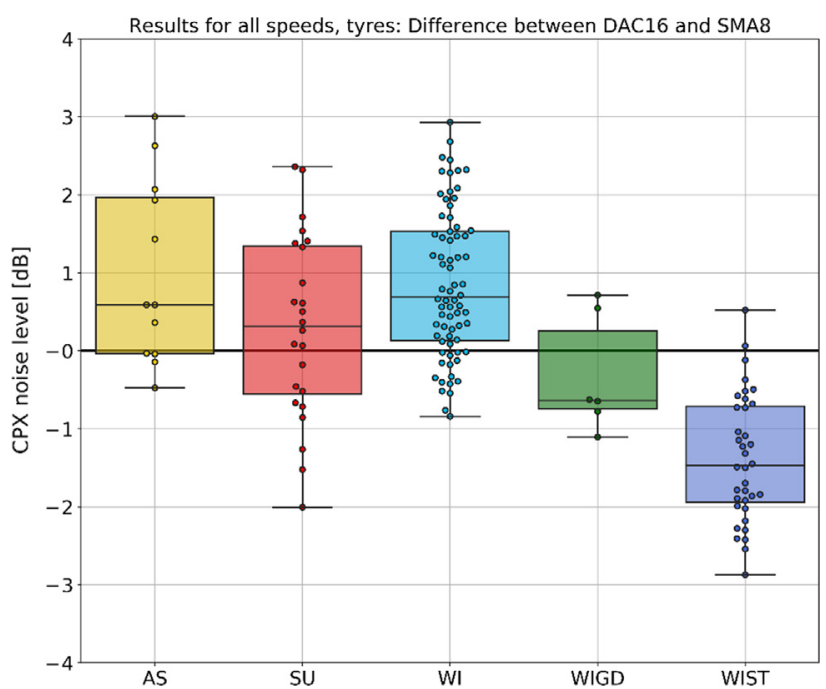

Fig. 10. Difference between the noise levels for the two test tracks. Positive values indicate that DAC 16 was noisier and negative values indicate that SMA 8 was noisier. Zero in the vertical axis corresponds to equality between measurements on DAC 16 and SMA 8.

in Table 3. The measurement length was $300 \mathrm{~m}$ for each repetition and the surface was in dry condition (Table 4).

It should be stressed that studded winter tyres are not allowed in Poland and this certainly affects the surface characteristics [20]. The objective when selecting the test surfaces here is, however, not to compare road wear processes. The idea is to use surfaces that are representative for the tests performed here and use them as standard surfaces. As a consequence, by standardizing road surfaces, performing the necessary temperature corrections predicted in the CPX (Close Proximity Method) standard [8], it is possible to compare how different tyres will perform, which is the objective of this text.

\subsection{Tyre/road noise}

The Close Proximity Method (CPX) was employed in order to evaluate the different tyres in accordance with the ISO/FDIS 11819-2, which was later published as ISO 11819-2 [8]. The noise measurements were performed by the Gdansk University of Technology (TUG) as shown in Fig. 1. The selected test speeds were 30, 50 and $80 \mathrm{~km} / \mathrm{h}$, and a minimum of two, yet usually, four runs were made in each test condition. In this paper, when individual data points are shown, they represent the average result for all runs with the same tyre, road section and test speed, i.e. the average of a minimum of two or more commonly four runs.

\subsubsection{Noise results normalization to the reference temperature}

All measurement results have been normalized to a reference air temperature of $10{ }^{\circ} \mathrm{C}$, in order to minimize that varying temperatures during the measurements affect the results. Although air, road and tyre temperatures were measured, only air temperatures were used for normalization. This reference temperature $10{ }^{\circ} \mathrm{C}$ was chosen, contrary to the $20^{\circ} \mathrm{C}$ which is often used in other cases, since it is rather similar to the average temperature during the measurements; thus minimizing the corrections. The correction procedure described in the ISO/DTS 13471-1, which was later published as ISO 13471-1 [21], was used. The maximum corrections were between -1.3 and $+1.4 \mathrm{~dB}$. This follows from air temperatures varying for the vast majority of measurements between 1
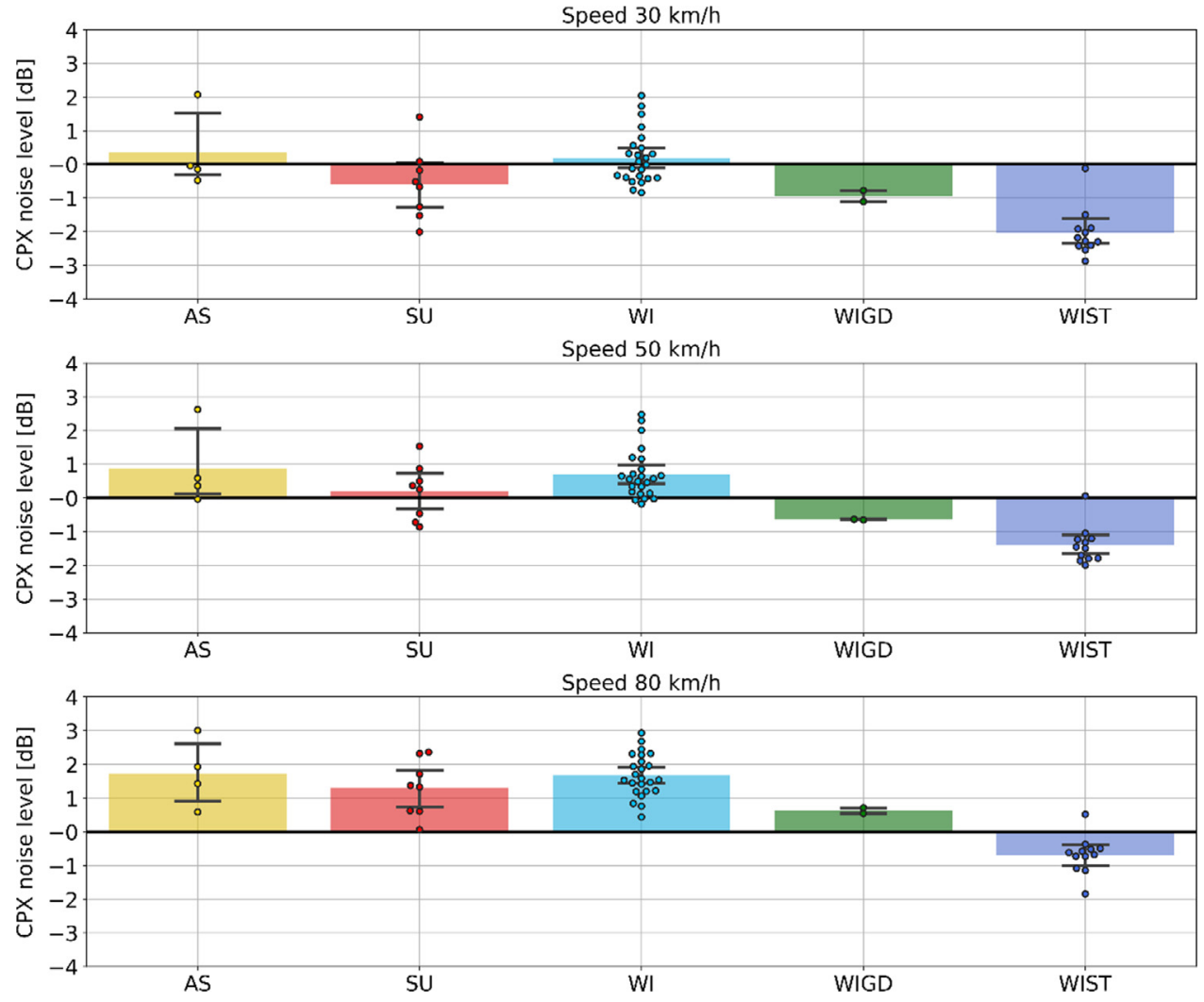

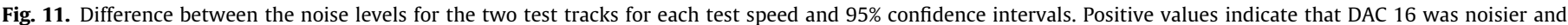
negative values indicate that SMA 8 was noisier. Zero in the vertical axis corresponds to equality between measurements on DAC 16 and SMA 8. 
and $15{ }^{\circ} \mathrm{C}$, but there were a few tyres tested at down to $-4{ }^{\circ} \mathrm{C}$ and a few tested at up to $+26^{\circ} \mathrm{C}$ air temperatures (although the latter were made in the beginning of April there was an unusual heat wave then). Given the uncertainty in the temperature coefficients, we estimate that the varying temperatures result in a maximum uncertainty of up to $\pm 0.3 \mathrm{~dB}$, which probably is the single largest uncertainty contribution.

\section{Results and discussion}

\subsection{Results in general}

To perform the statistical analysis, including confidence intervals, the non-parametric boostraping method was applied [22]. In this method, values need not be normally distributed. Initially, the data is analysed by separating the results into different tyre categories only. Fig. 2 indicates that WIST tyres resulted in significantly higher CPX noise levels and the WIGD resulted in somewhat lower noise levels. Note also the clusters of data that are visible in all tyre categories, perhaps except the WIST. This is a result of grouping results for different CPX test speeds (30, 50 and $80 \mathrm{~km} / \mathrm{h}$ ). WI results have a larger variation when compared to the other categories, meaning that there is a more substantial difference in the acoustical performance of different winter tyres. By comparing the median values for each category, while it is clearly visible that the studded tyres group is the noisiest, by considering the median values, the difference between WI, SU, and AS tyres is not large. It is also noteworthy that the WIGD category resulted in the lowest median value of all. Note that each data point is the result of repeated runs with the same test tyre and speed.

The results may be further analysed in frequency spectra as shown in Fig. 3 where the solid lines represent the mean spectra for each tyre category and the shadowed region indicates the 95\% confidence interval for the mean value on each frequency band. While the confidence intervals are relatively wide, leading to an overlap between most groups, it is remarkable that the studded tyres have increased noise levels in the entire frequency range between $315 \mathrm{~Hz}$ and $10 \mathrm{kHz}$. Also note that for frequencies higher than $4 \mathrm{kHz}$ WIST have a plateau region where noise levels are
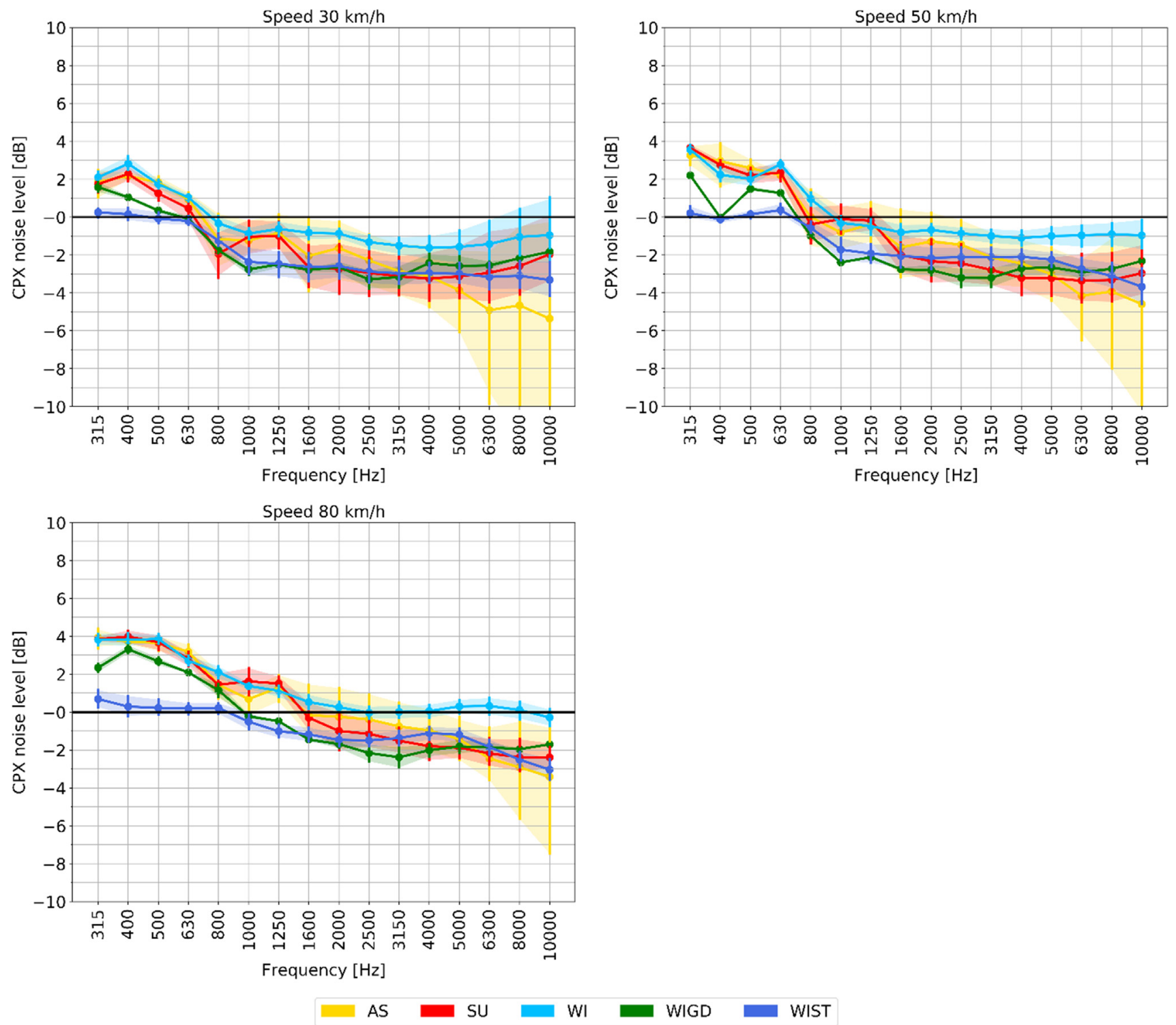

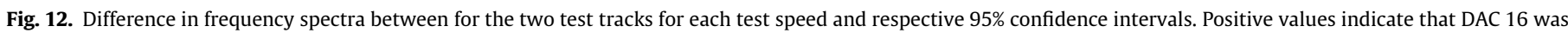
noisier and negative values indicate that SMA 8 was noisier. Zero in the vertical axis corresponds to equality between measurements on DAC 16 and SMA 8. 
constant, unlike other spectra that exhibit a drop-off from the peak in the $800 \mathrm{~Hz}$ third-octave band. This is believed to be caused by the impact of the studs against the road surface. The WIGD tyres have a slight increase in noise levels for frequencies of $8 \mathrm{kHz}$ and higher, which could be related to the impact of the small hard particles in the tyre tread. The most remarkable feature found in the results here is that the studded tyres have this overall noise level increase in the entire frequency spectra.

The CPX results break down into the three test speeds is shown in Fig. 4 with the average noise for each tyre category and speed, including the $95 \%$ confidence interval for the mean values. The data points have been displaced horizontally within each bar to minimize overlapping and allow a better visualization. Note that, for each test speed, AS, SU and WI tyres have, in average, no significant difference in noise levels, however, WIST are significantly noisier and WIGD are significantly quieter. When looking at the frequency spectra in Fig. 5, the WIST spectrum differentiate itself from the others at all speeds, however, the WIGD spectra have significantly increased noise levels for frequencies higher than $8 \mathrm{kHz}$ at $30 \mathrm{~km} /$ $\mathrm{h}$, however, this difference decreases at $50 \mathrm{~km} / \mathrm{h}$ and the spectrum overlaps the AS for $80 \mathrm{~km} / \mathrm{h}$. It is also noteworthy that WIGD is among the quietest for lower frequencies, between $315 \mathrm{~Hz}$ and $1 \mathrm{kHz}$, where vibrational mechanisms are dominating. Moreover, this tyre category is the quietest when looking at frequencies of $800 \mathrm{~Hz}$ up to $5 \mathrm{kHz}$, where air-related noise generation mechanisms are dominant. The frequency spectra also indicate that SU tyres become slightly noisier at frequencies of $1.6 \mathrm{kHz}$ and
$2.0 \mathrm{kHz}$, and that this feature becomes more expressive as the speed increases from $30 \mathrm{~km} / \mathrm{h}$ up to $80 \mathrm{~km} / \mathrm{h}$.

\subsection{Winter tyres for northern and central Europe}

The winter non-studded tyres were previously analysed as a single group, however, some of those tyres were optimized for central European conditions while others were optimized for northern European ("Nordic") conditions. By splitting the results for WI tyres into Nordic and central European, the differences in the average noise level for each test speed are presented in Fig. 6. The difference seems to be relatively small, with Nordic winter tyres being about $1 \mathrm{~dB}$ quieter. The upper limit for the confidence interval for Nordic tyres overlaps the lower limit for central European tyres at the speed of $80 \mathrm{~km} / \mathrm{h}$. For $30 \mathrm{~km} / \mathrm{h}$ and $50 \mathrm{~km} / \mathrm{h}$ the intervals are close to each other, yet not overlapping. This relatively small difference is further studied in Fig. 7 with the frequency spectra. While the low-frequency behaviour is similar for the two tyre categories, between $315 \mathrm{~Hz}$ and $800 \mathrm{~Hz}$, a significant difference is visible for frequencies from $1 \mathrm{kHz}$ up to 3 or $4 \mathrm{kHz}$, depending on the test speed. The most significant difference between Nordic and central European tyres is found at the frequencies $1.25 \mathrm{kHz}$ and $1.6 \mathrm{kHz}$, reaching a maximum of about $5 \mathrm{~dB}$ difference between the two spectra. This difference is believed to be related to the different tread design (softer rubber and more sipes for the Nordic tyres), which affects air-related noise generation mechanisms.
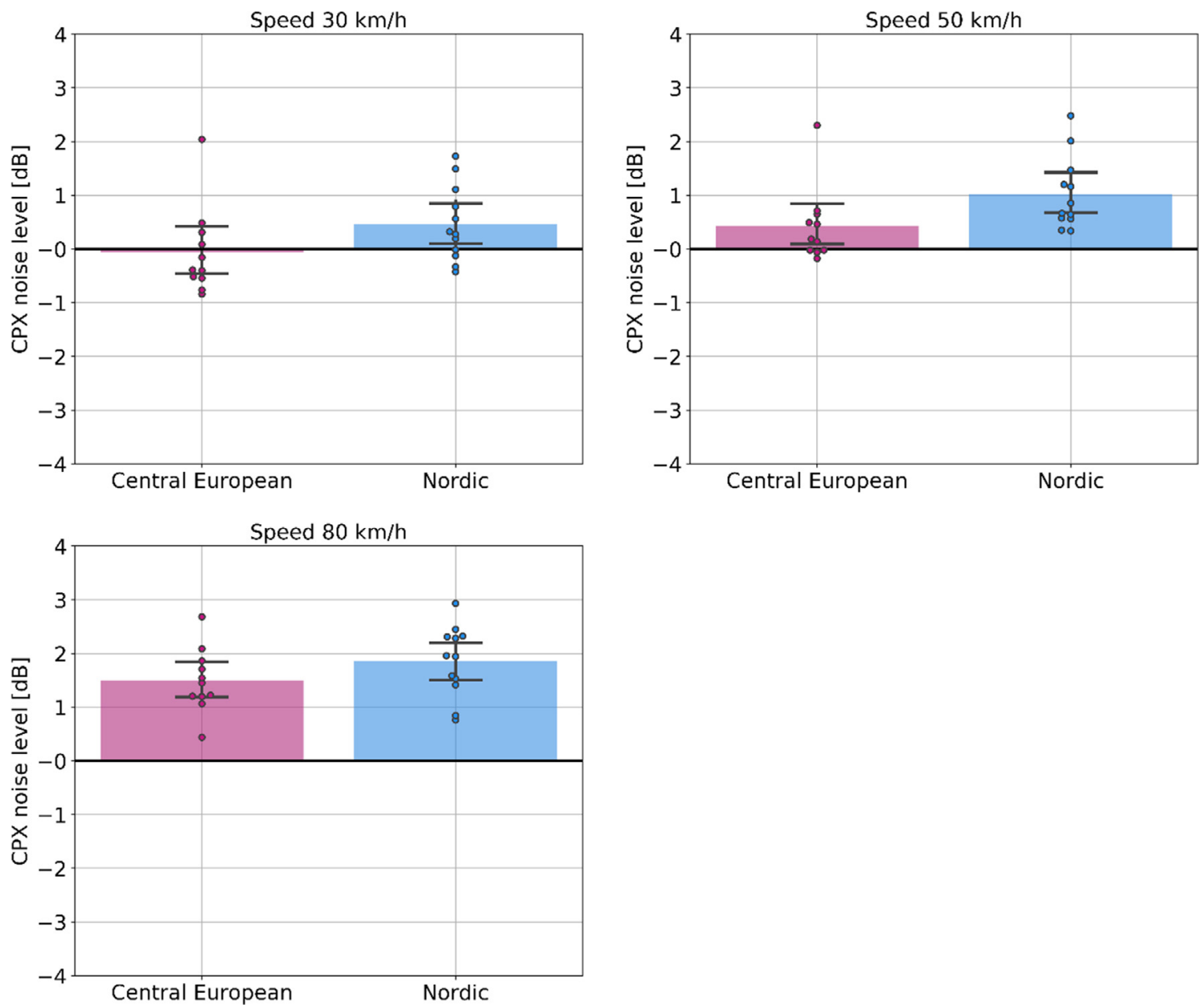

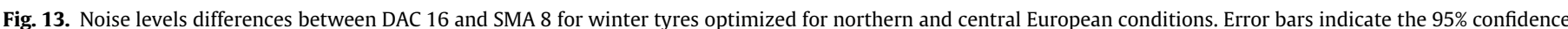

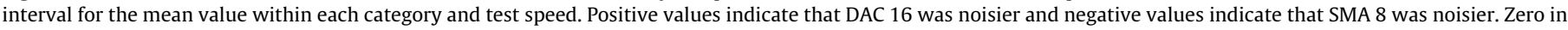
the vertical axis corresponds to equality between measurements for tyres optimized for central Europe and northern Europe. 


\subsection{Difference between tyres in new and used conditions}

A small sample of three regular winter tyres and one studded winter tyre was analysed in both new and used conditions. The studded tyre had a tread depth of $10 \mathrm{~mm}$ in new condition and $8 \mathrm{~mm}$ in used condition. Stud protrusion was approximately $1.5 \mathrm{~mm}$ in new and $0.5 \mathrm{~mm}$ in used condition. Considering all the tested tyres evaluated in both new and used conditions, the tread depth decreased between 1 and $3 \mathrm{~mm}$.

As the sample size is small, statistical interpretation of this data is limited. The average noise level presented in Fig. 8 indicates that the noise level decreases for the tyres in used conditions when comparing to the same tyres in new conditions. This reduction was more expressive for the WIST tyre and especially at speeds of $30 \mathrm{~km} / \mathrm{h}$ and $50 \mathrm{~km} / \mathrm{h}$. Looking at the frequency spectra in Fig. 9, the WIST tyre in used condition has an overall reduction in the frequency spectra, however, it maintains its plateau region for frequencies higher than $4 \mathrm{kHz}$ approximately. The lowerfrequency region, between $315 \mathrm{~Hz}$ and up to $800 \mathrm{~Hz}$, becomes more similar to a non-studded winter tyre, especially at $80 \mathrm{~km} /$ h. For frequencies higher than $1 \mathrm{kHz}$ there still is a difference between studded and non-studded tyres, both for new and used conditions. For regular winter tyres the vibrational-dominated frequency region remains approximately the same, up to $630 \mathrm{~Hz}$, while the peak at $800 \mathrm{~Hz}$ indicates a noise reduction, and the frequencies up to $2 \mathrm{kHz}$ also present a decrease in noise levels. This difference is, however, reduced with increasing speed. For $80 \mathrm{~km} / \mathrm{h}$, the spectra for new and used condition overlap each other.

The observed differences between new and used conditions are significant, yet similarly, large differences between the acoustical performance of tyres in new and used conditions have previously been observed by [23]. The authors showed that winter tyres noise levels decreased by $2 \mathrm{~dB}$ when comparing new tyres and used tyres. In that case, the tested tyres had a tread depth of $8 \mathrm{~mm}$ when new and $6 \mathrm{~mm}$ when used. Further investigations are required in order to draw statistically significant conclusions on the acoustical performance of tyres in different states of use and wear.
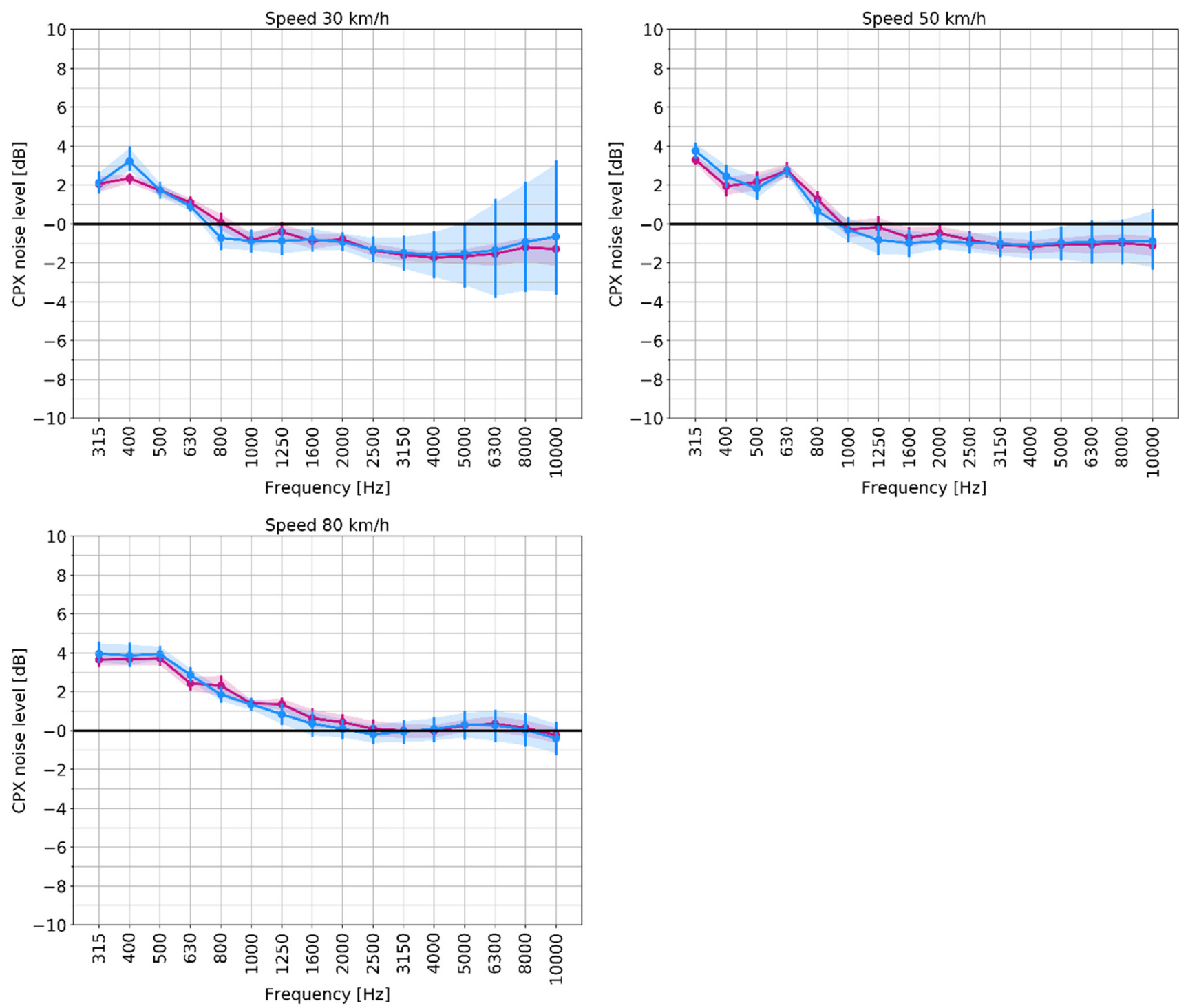

WI - Central Europe

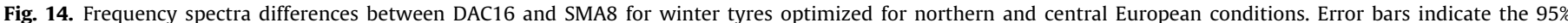

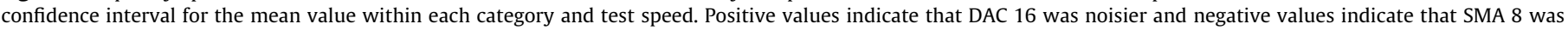
noisier. Zero in the vertical axis corresponds to equality between measurements for tyres optimized for central Europe and northern Europe. 


\subsection{Difference between the two test tracks}

\subsubsection{For overall data}

The effect of the two test tracks is studied in this section. For this purpose, noise level and noise spectra for the SMA 8 surface were subtracted from the DAC 16 surface. This means that positive values in this section indicate that the DAC 16 test section was noisier than SMA 8 test section. The results are presented in Fig. 10. For AS and WI most of the results distribution is on the positive region of Fig. 10, and for SU the median is also on the positive side. For WIGD the median is found on the negative side and the more extreme difference is found on the WIST category that almost the entire results distribution is on the negative side, meaning that such tyres are noisier on the SMA 8 surface. The largest variation was found in the SU tyre category, from $-2 \mathrm{~dB}$ to approximately $+2.5 \mathrm{~dB}$. This tyre category seems to be more sensitive to the different test tracks. The smallest variation was found in the WIGD tyre, having approximately $2 \mathrm{~dB}$ difference. As previously, the speed effect on data is investigated and the results are broken down into the three different test speeds as presented in Fig. 11, including the $95 \%$ confidence intervals. For $30 \mathrm{~km} / \mathrm{h}$ the SU tyres are noisier at the SMA 8 surface, yet as the test speed increases, such tyres become noisier on the DAC 16 surface instead. A similar behaviour is observed for the WIGD tyres. The WI tyres have a more neutral behaviour for lower speeds, presenting no significant differentiation between the two test tracks at speeds of $30 \mathrm{~km} / \mathrm{h}$, however, as speed increases, WI become noisier on the DAC 16 surface. The studded tyre results differ from the previous groups as it is noisier on the SMA 8 surface for all tested speeds. It is expected, however, that with increased speeds, the studded tyres will also become noisier on the DAC 16 surface, assuming that the trend observed in Fig. 11 holds for speeds higher than $80 \mathrm{~km} / \mathrm{h}$.

Frequency spectra comparing the two test tracks are presented in Fig. 12. Similar to the previous analysis, positive values indicate that the DAC 16 surface was noisier and negative values indicate that the SMA 8 surface was noisier. For lower frequencies, up to $630 \mathrm{~Hz}$ for $30 \mathrm{~km} / \mathrm{h}$, the DAC 16 surface was noisier, which can be understood as a result of a rougher macrotexture, as indicated in this paper by a higher MPD value, and a larger maximum aggregate size, both of which contribute to increased vibrations in the tyre structure. The frequency range at which the DAC 16 surface is noisier increases with speed, from $630 \mathrm{~Hz}$ or $800 \mathrm{~Hz}$ at $30 \mathrm{~km} /$ $\mathrm{h}$, depending on the tyre group, up to $2 \mathrm{kHz}$ for $80 \mathrm{~km} / \mathrm{h}$ for WI, for instance. It is also noteworthy that the dispersion increases for higher frequencies in some groups. This is especially visible for the AS tyres at speeds of $30 \mathrm{~km} / \mathrm{h}$ and frequencies higher than $5 \mathrm{kHz}$. This dispersion is, however, reduced as speed increases. Studded tyres seem to be neutral with regards to the tested surfaces for frequencies up to approximately $630 \mathrm{~Hz}$. For WI tyres, a relatively larger dispersion is found for $30 \mathrm{~km} / \mathrm{h}$ and frequencies higher than $8 \mathrm{kHz}$.
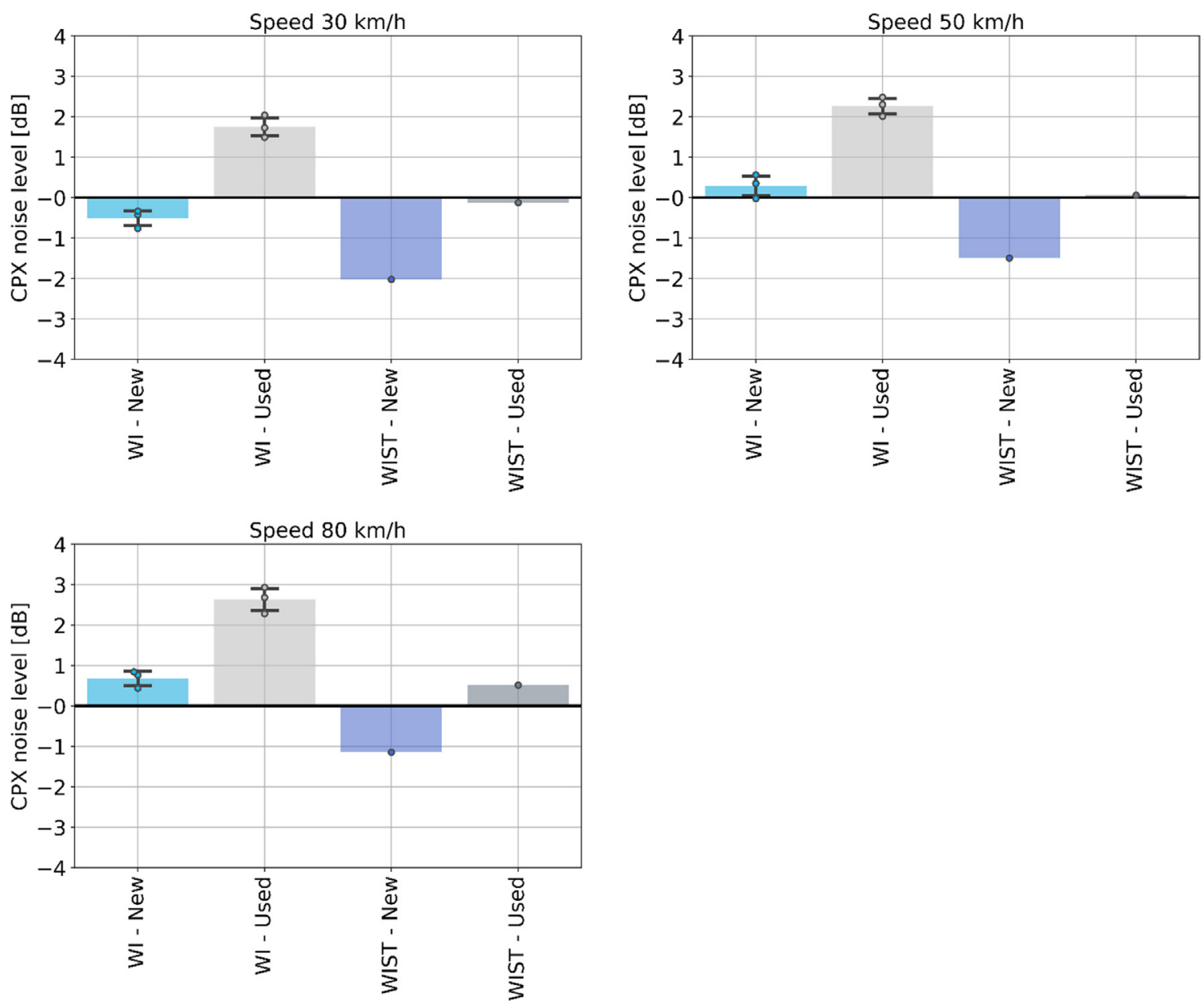

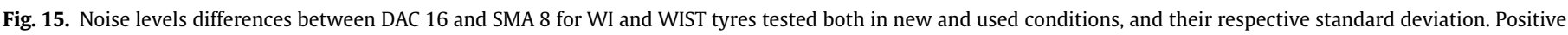

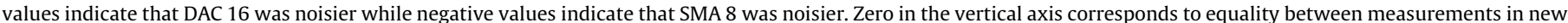
and used conditions. Note that the sample size for this comparison is small. 


\subsubsection{For tyres optimized for northern and central Europe}

To further investigate the role of the two surfaces, the performance of winter tyres optimized for northern and central Europe is also compared, the results are shown in Fig. 13. Again, positive values indicate that DAC 16 surface was noisier and negative values indicate that SMA 8 was noisier. Note that the WI tyres for northern Europe were significantly noisier on the DAC 16 surface than they were on the SMA 8 surface. The central European tyres do not have significantly distinct noise levels between the two surfaces, however, they become slightly noisier on the DAC 16 surface as testing speed increases to $50 \mathrm{~km} / \mathrm{h}$ and $80 \mathrm{~km} / \mathrm{h}$. Fig. 14 shows the frequency spectra, indicating that the two winter tyre categories analysed here have rather similar performance, however, a relatively large dispersion is found for frequencies higher than $5 \mathrm{kHz}$ and lower speeds, such as $30 \mathrm{~km} / \mathrm{h}$.

\subsubsection{For tyres in new and used conditions}

The limited sample used to evaluate the difference between tyres in new and used conditions also allows a comparison
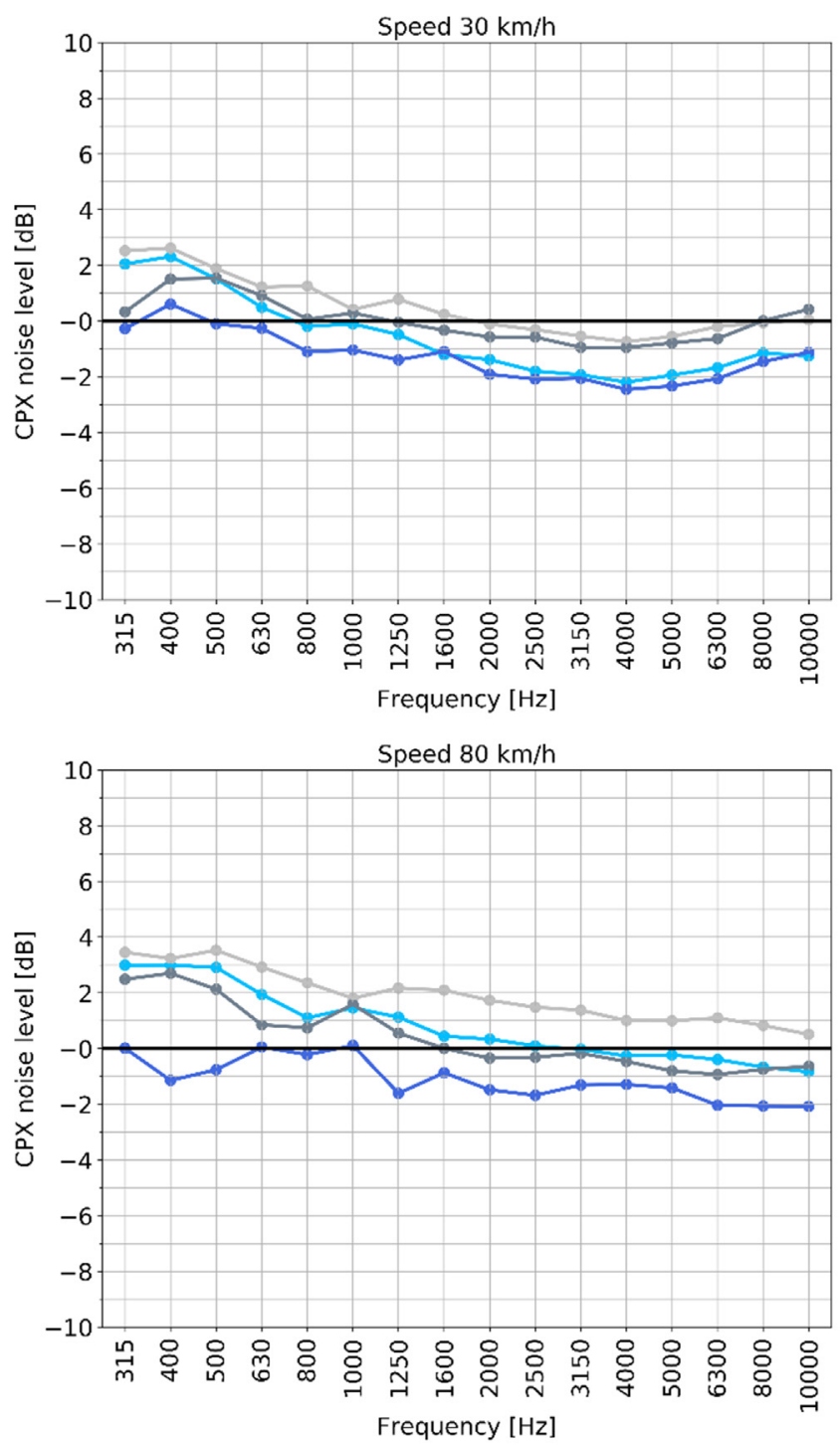

between the test tracks. The average values and respective standard deviations are presented in Fig. 15 for each test speed. The effect of tyre usage and wear seem to lead to a more significant differentiation of the two test tracks and especially for higher testing speeds. By analysing the frequency spectra in Fig. 16 it is noteworthy that the most dramatic changes take place at lower frequencies and thus the track differentiation seems to be linked to vibrational properties of the tyres, that change as the tyre ages and wears out.

\subsection{The acoustical effect of the studs}

A closer look at the effects of studs is presented in Fig. 17. In this figure, the spectra of two tyres which are fitted with studs are compared to the spectrum of two identical tyres not fitted with studs (the latter tyres were removed from the production just before studs were mounted). Therefore, the only nominal difference between the two tyres is due to the insertion of studs. This gives a quite dramatic difference, $5-7 \mathrm{~dB}$ over the frequency range $200-5000 \mathrm{~Hz}$, but with an extra $2 \mathrm{~dB}$ at $1000-2000 \mathrm{~Hz}$, and with

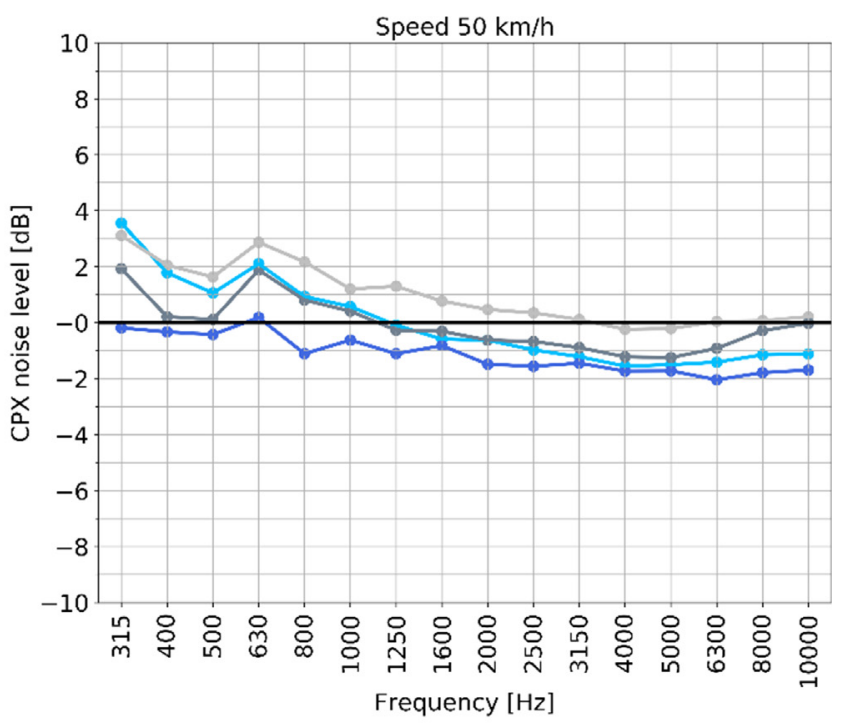

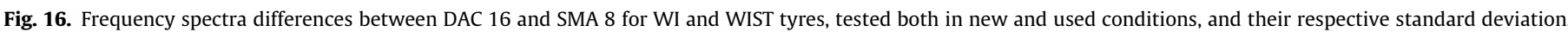

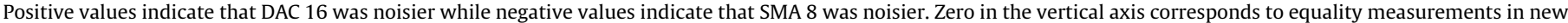
and used conditions. Note that the sample size for this comparison is small. 
the typical high-frequency boost above $5000 \mathrm{~Hz}$. One should note that this was done for new and unworn tyres and with studs having 1-2 $\mathrm{mm}$ protrusion above the tread rubber surface, and after some wear the stud effect will decrease. It should be noted that the noise levels for studded tyres decreases somewhat after an initial wear due to a decrease in the stud protrusion.

Perhaps the most surprising finding is that the studs increase the noise levels all over the audible frequency range. One would intuitively assume that the impact and the scratching of the studs on hard asphalt would create high-frequency noise, above $1000 \mathrm{~Hz}$ or so, and in particular what is observed above $4000-5000 \mathrm{~Hz}$ [4]. But, evidently, the studs have an effect also at medium and low frequencies. It is likely that the forces results from the studs impacting the road surface create reaction forces in the rubber tread, thus increasing the vibrations in the tyre, which are generally considered to play an important role mainly at frequencies below about $1000 \mathrm{~Hz}[4]$.
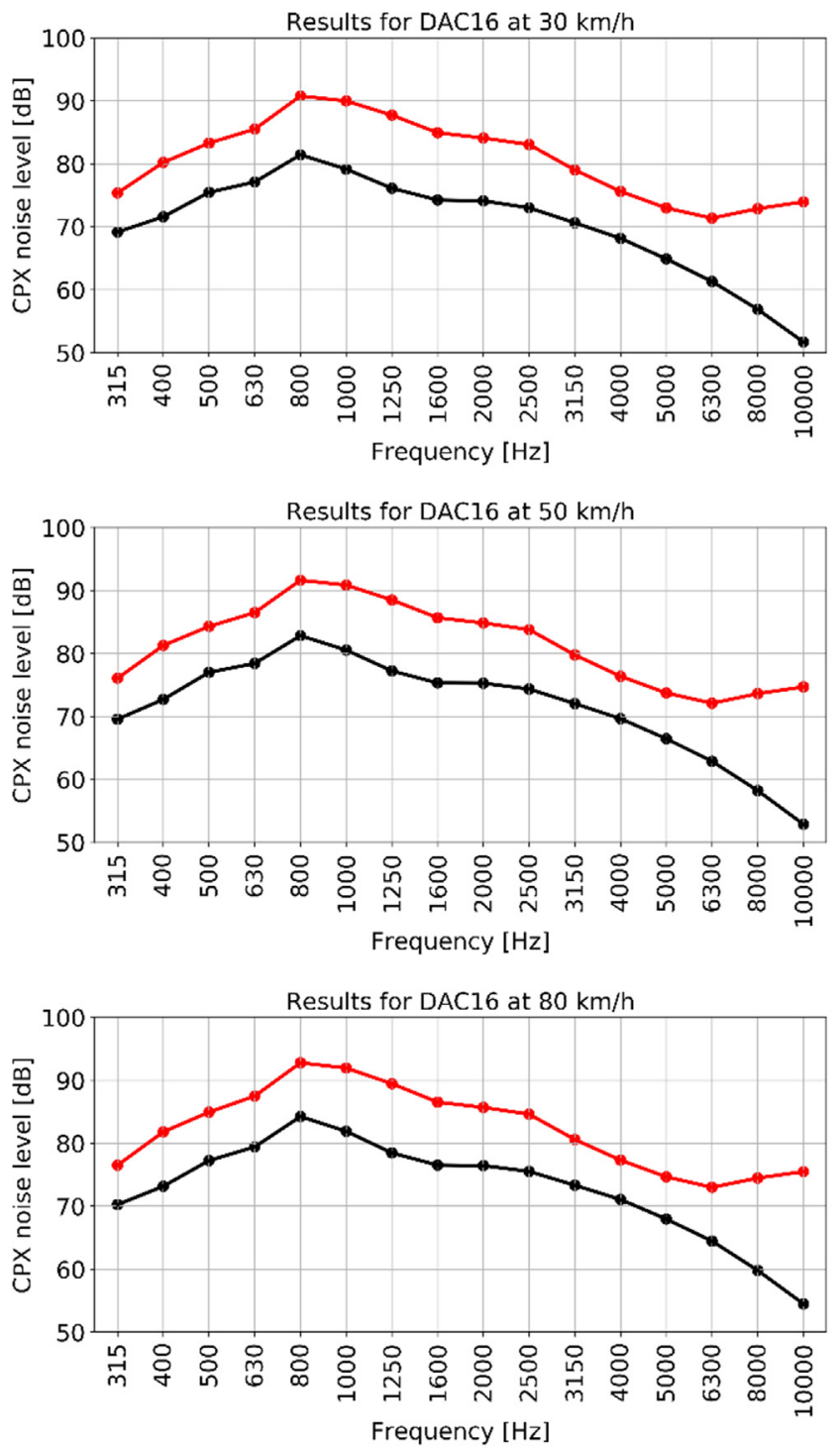

Tyres with studs

\subsection{Measured values and labelled values}

The measured data also allowed a comparison between the CPX results and the noise levels found on each tyre label. The tyre labelled value is regulated by the European Parliament and Council Regulation number 1222/2009 [24]. The difference between the measured and labelled values are presented in Fig. 18 for each test section and speed. Note that while the CPX measurements lead to higher noise levels in all cases, there is no significant difference between the different tyre categories. Note also that the difference between labelled noise values and measured CPX values for a given test speed seems to be statistically unaffected by the test tracks. Results for the DAC 16 and SMA 8 surfaces seem to deviate equally much. This leads to the analysis found in Fig. 19 where the AS, SU and WI tyres were grouped according to their noise classes (G1, G2 and G3) in the tyre labelling regulation, and the relationship to the labelled noise level was analysed. Note that there is no significant
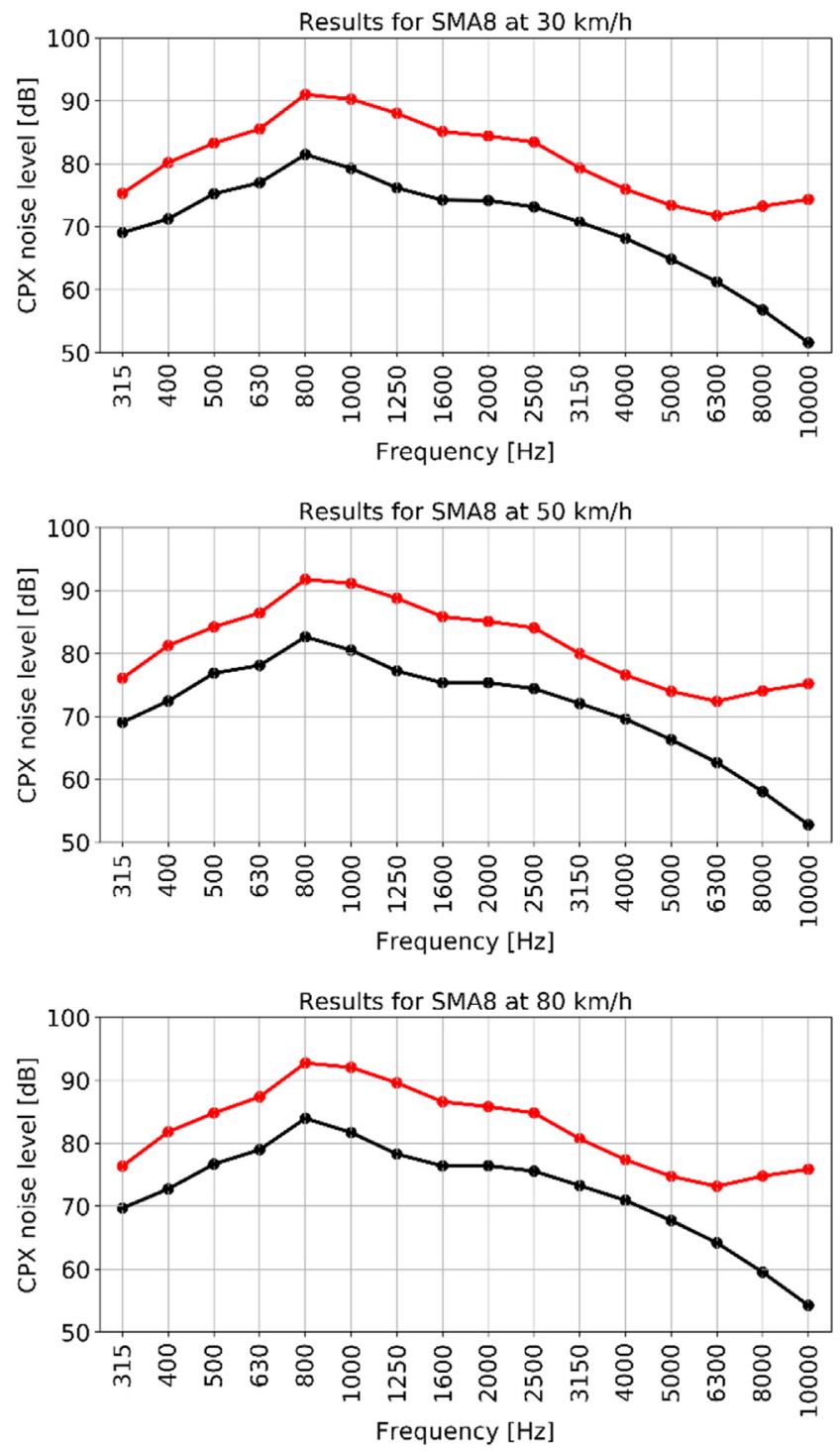

Tyres without studs

Fig. 17. Frequency spectra for comparing two tyres fitted with studs and two other tyres without studs. Except for the studs, the tyres are nominally identical. 


\section{Difference between measured and labelled noise values}
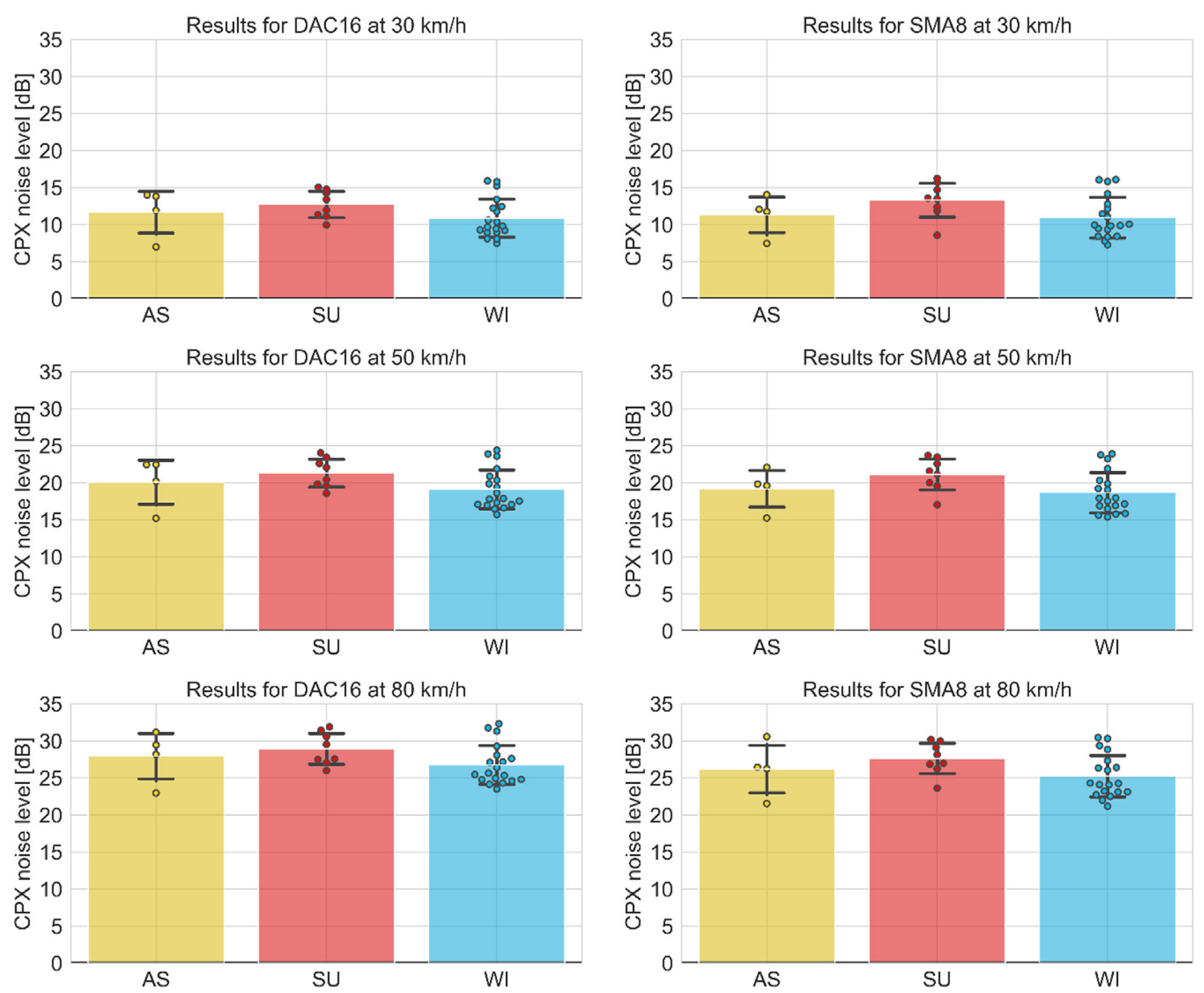

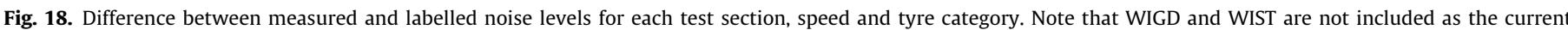
labelling regulations do not apply to retreaded and studded tyres. Zero in the vertical axis corresponds to equality between labelled and measured CPX values.

correlation between the labelled noise levels and the noise levels measured with the CPX method. Note also that WIGD and WIST are not included in this comparison as the current labelling regulations do not apply to retreaded and studded tyres.

It is apparent in Fig. 19 that there is a large "bias" (difference in horizontal direction) between the measured values and the labelled ones. For $80 \mathrm{~km} / \mathrm{h}$ it is $26-27 \mathrm{~dB}$ and at $50 \mathrm{~km} / \mathrm{h}$ it is around $20 \mathrm{~dB}$. The reasons for this are:

- Difference in speed for the $50 \mathrm{~km} / \mathrm{h}$ values (labelling is always at a nominal speed of $80 \mathrm{~km} / \mathrm{h}$ )

- Difference in measuring method (CPX versus $\mathrm{CB}$, i.e. coast-by, mainly caused by the microphone locations)

- Difference between the test surfaces; labelling is made on several realizations on test tracks of ISO 10844, while measurements in this project were made on a trafficked SMA 8.

With regard to speed influence between 50 and $80 \mathrm{~km} / \mathrm{h}$, this is usually around $6 \mathrm{~dB}$ (speed exponent 30), which means that the bias is increased from 20 to $26 \mathrm{~dB}$, which is very close to the bias $(26-27)$ at $80 \mathrm{~km} / \mathrm{h}$. Therefore, we assume that the average bias is $26.5 \mathrm{~dB}$ at $80 \mathrm{~km} / \mathrm{h}$.

The bias due to the method is discussed at some length in [25], where it is concluded to be $22.5 \mathrm{~dB}$. If we subtract $22.5 \mathrm{~dB}$ from the bias of $26.5 \mathrm{~dB}$, we have a resulting bias of "only" $4 \mathrm{~dB}$. This is within the expected variation between ISO 10844 surfaces [26]; especially as our test surface was an in-service SMA 8 that was chosen as a proxy for a real ISO 10844 surface. It is reported earlier that road surfaces subject to traffic give higher noise levels than similar test track surfaces [27]. When these biases are compensated for, the data in Fig. 19 look like in Fig. 20. It is then even more apparent that there is no correlation between labelled and measured values. More investigations are needed to understand the reasons for this lack of correlation.

\section{Conclusions}

Acoustic performance of different categories of tyres has been evaluated for two different road surfaces and three different speeds, with focus on winter tyres, but with some normal ("summer") tyres for reference. The winter tyres were evaluated by splitting this group into all season tyres, tyres optimized for central European and for Nordic climates as well as studded tyres. The results indicate that the difference with respect to noise is rather small if studded tyres are excluded. When considering the average values of both surfaces and all tested speeds, winter studded tyres were approximately $7 \mathrm{~dB}$ noisier than the other tyre groups.

Nordic winter tyres were up to $1 \mathrm{~dB}$ quieter than central European tyres on average levels. This difference appears especially for 

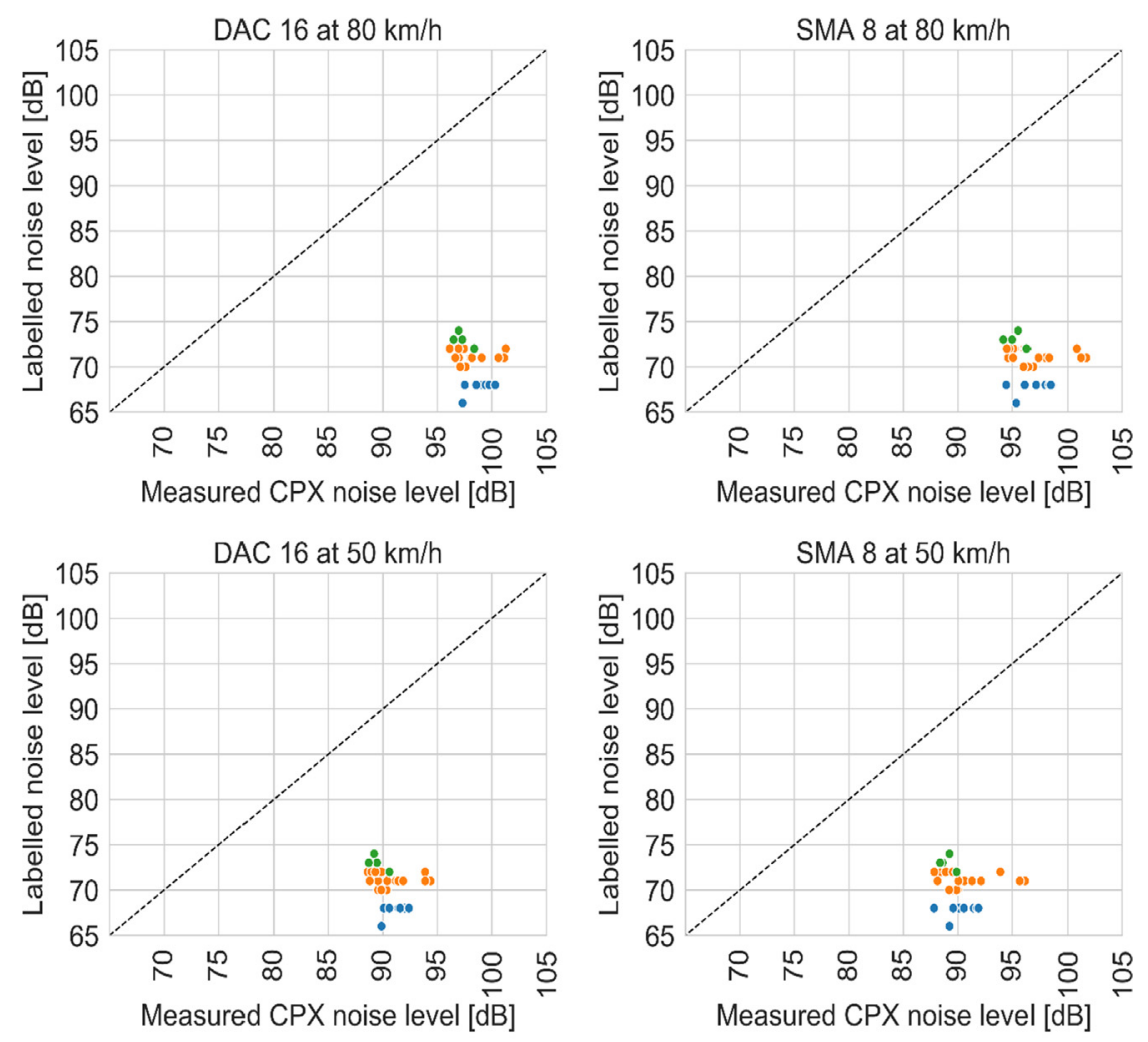

Label Group $\bullet \quad$ G1 $\quad$ G2 $\bullet \quad$ G3

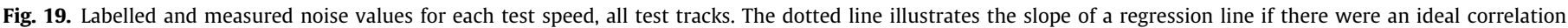
between the labelled and measured values.
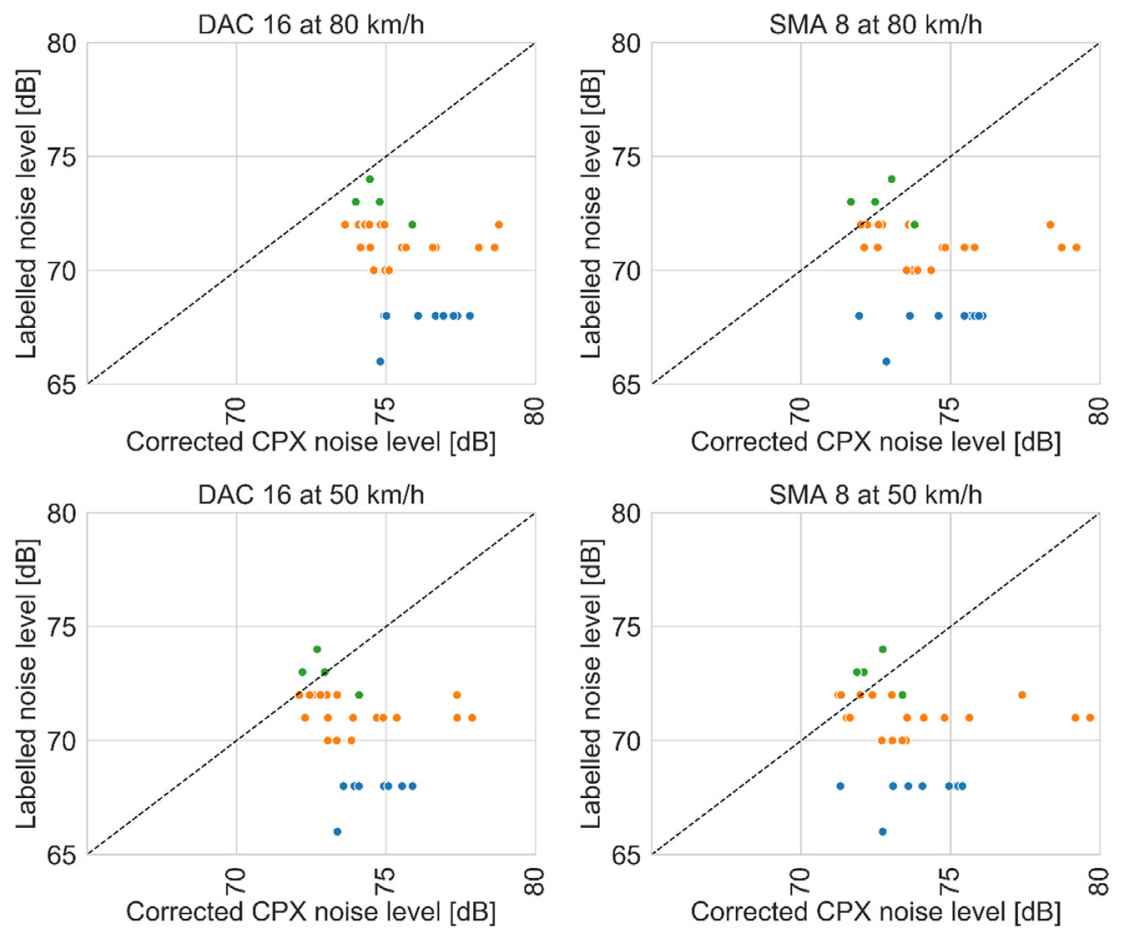

Label Group $\quad \bullet \quad$ G1 $\quad$ G2 $\quad$ G

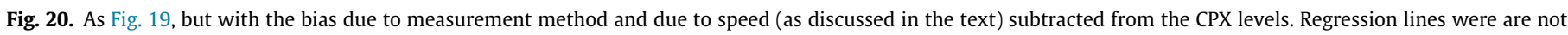
shown here due to the lack of correlation between measured and labelled values. 
frequencies of $1.25 \mathrm{kHz}$ and $1.6 \mathrm{kHz}$. The difference is attributed to the tyre tread design which affects air-related noise generation mechanisms. That might be linked to the difference in tyre rubber hardness between winter tyres optimized for northern and central European climates, where generally the rubber compound is softer the lower temperatures, they are assumed to run in. Unfortunately, rubber hardness measurements were not done as a part of this study and therefore no data is available to draw some conclusions regarding the impact of the rubber tyre hardness on their noise level.

Winter tyres with studs have a significantly distinct frequency spectrum when comparing to all other tested tyre types. This difference is expressed not only by an overall increase of the spectrum but also by an approximately flat region in the spectra for frequencies higher than $4 \mathrm{kHz}$, as opposed to a decreasing trend found for other tyre groups. This high-frequency distinction is related to the impact of the studs on the road surface. When examining the spectrum for tyres with hard particles, instead of regular studs, a modest, yet statistically significant increase was found for frequencies higher than approximately $6.3 \mathrm{kHz}$. This supports the idea that the high-frequency differentiation is connected to impacts of hard objects in the tread on the road surface. The effect of removing the studs was also evaluated, leading to differences not only at the higher frequencies but also at medium and low frequencies. This indicates that the studs also have an important role in generation mechanisms at lower frequencies, affecting tyre vibrations.

When comparing new and used conditions, the results showed that winter tyre noise levels decrease by $2 \mathrm{~dB}$ in used condition when comparing to the new condition. Use and wear lead to a more significant differentiation of the two test tracks, especially for higher testing speeds and especially for lower frequencies, connected to vibrational properties of the tyres.

The road surface certainly has a major effect on tyre/road noise. While more than $75 \%$ of the winter tyres without studs that were tested were noisier on the DAC 16 surface (which is actually more like an SMA 16 surface), this picture changes when looking at tyres with studs. Almost all of the studded tyres were noisier on the SMA 8 surface. The frequency spectra show that, for almost all tested tyres, the levels are higher for DAC 16 at lower frequencies, and the higher the test speed, the more dominating this behaviour will be. For the speed of $30 \mathrm{~km} / \mathrm{h}$, the DAC 16 surface is noisier for frequencies up to approximately $630 \mathrm{~Hz}$; for $50 \mathrm{~km} / \mathrm{h}$ it is louder for frequencies up to $800 \mathrm{~Hz}$; and for $80 \mathrm{~km} / \mathrm{h}$ the DAC 16 surface was noisier for frequencies up to $1 \mathrm{kHz}$ or $1,6 \mathrm{kHz}$, depending on the tyre group. This is a result of impact and vibrational noise mechanisms. In contrast to this, studded tyres were somewhat quieter on the DAC 16 surface than on the SMA 8 surface, suggesting that as the largest aggregate size increases, the noise level for studded tyres decreases. This does not mean that reducing the maximum aggregate size should be avoided where studded tyres are allowed. The selection process of the surface layer should be based on a holistic approach including durability, friction, wear and rolling resistance characteristics of the selected surface layer. This discussion is, however beyond the scope of this text.

Regarding a comparison between measured and labelled values, there appeared to be no correlation. More investigations are needed to fully comprehend the lack of correlation. This is reflected in a recent call for new research about this matter [28].

The rather large difference between studded tyres and nonstudded winter tyres recorded here calls for an update of the correction in the traffic noise prediction method CNOSSOS-EU [29], where it is around $2 \mathrm{~dB}$ for the overall level. Here, we found the difference to be around $7 \mathrm{~dB}$ for new tyres and $4 \mathrm{~dB}$ for moderately worn tyres, but for substantially worn tyres (studs) the difference will be even lower. Our estimation is that around $4 \mathrm{~dB}$ would be a more typical difference for an average condition of studded tyres; i.e. CNOSSOS-EU should be updated to about double the present correction.

\section{Conflict of interest}

None declared.

\section{Acknowledgements}

The winter tyres measurements were performed within a project at VTI financed by the Swedish Transport Administration. The first author has his PhD programme sponsored by the Swedish Transport Administration and by VTI. The CPX measurements were assisted by Dr Piotr Mioduszewski and Dr Ryszard Woźniak at the Technical University of Gdansk in Poland. Dr Mikko Liukkula and Nokian Tyres Finland contributed with some of the tested tyres from Nokian.

\section{References}

[1] European Environment Agency. Noise in Europe 2014. EEA Report. Luxembourg: European Environment Agency; 2014. Contract No.: 10/ 2014.

[2] World Health Organization. Burden of disease from environmental noise: quantification of healthy life years lost in Europe. Copenhagen: World Health Organization; 2011.

[3] Hänninen O, Knol AB, Jantunen M, Lim T-A, Conrad A, Rappolder M, et al. Environmental burden of disease in Europe: assessing nine risk factors in six countries. Environ Health Perspect 2014;122(5):439-46.

[4] Sandberg U, Ejsmont JA. Tyre/road noise reference book. Kisa, Sweden: Informex; 2002. p. 616.

[5] Gent AN, Walter JD. The pneumatic tire. Washington DC, USA: NHTSA; 2005. p. 699.

[6] Bendtsen H. NordTyre - Tyre labelling and Nordic traffic noise. Copenhagen: Danish Road Directorate (DRD); 2015.

[7] Sandberg U, Ejsmont J. Noise emission, friction and rolling resistance of car tyres - Summary of an experimental study. Proc of NOISE-CON 2000, 2000. Newport Beach, California, USA, Also avaliable as VTI Reprint No. 339, VTI, Linköping, Sweden.

[8] International Organization for Standardization. ISO 11819-2: 2017. Acoustics Measurement of the influence of road surfaces on traffic noise - Part 2: The Close-proximity method. Geneva, Switzerland: International Organization for Standardization; 2017.

[9] Reithmaier W, Salzinger T. Determination of the state-of-the-art concerning rolling noise, rolling-resistance and safety properties of modern passenger car tyres. Munich, Germany: TÜV Automotive GmbH, Tire-/Wheel-Test-Center; 2002. Report No.: 20154112.

[10] Sandberg U, Hjort M. Relation between tyre/road noise and ice and snow friction of winter tyres. Austria: Inter-Noise; Innsbruck; 2013.

[11] International Organization for Standardization. ISO 10844: 1994. Acoustics Specification of test tracks for the purpose of measuring noise emitted by road vehicles. Geneva, Switzerland: International Organization for Standardization; 1994.

[12] International Organization for Standardization. ISO 13325: 2003. Tyres Coast-by methods for measurement of tyre-to-road sound emission. Geneva, Switzerland: International Organization for Standardization; 2003.

[13] Skov RSH. Analysis and comparison of methods, CPX and SPB, for measuring noise properties of road surfaces. Hamburg: Inter-Noise; 2016.

[14] Cesbron J, Klein P. Correlation between tyre/road noise levels measured by the Coast-By and the Close-ProXimity methods. Appl Acoust 2017;126:36-46.

[15] Li T. A state-of-the-art review of measurement techniques on tire-pavement interaction noise. Measurement 2018;128:325-51.

[16] ASTM International. ASTM F 2493-14: 2014. Standard Specification for P225/ 60R16 97S Radial Standard Reference Test Tire. Pennsylvania, United States: ASTM International; 2014.

[17] United Nations Economic Commissions for Europe (ECE). ECE R117 Rev 2: 2011. Uniform provisions concerning the approval of tyres with regard to rolling sound emissions and to adhesion on wet surfaces and/or to rolling resistance, Geneva, Switzerland, 2011.

[18] International Organization for Standardization. ISO 13473-1: 1997 Characterization of pavement texture by use of surface profiles - Part 1: Determination of Mean Profile Depth. Geneva, Switzerland: International Organization for Standardization; 1997.

[19] Arnberg PW, Burke MW, Magnusson G, Oberholzer R, Rahs K, Sjögren L. The Laser RST: Current Status. VTI särtryck 102. Linkoeping, Sweden: Swedish National Road and Transport Research Institute (VTI); 1991.

[20] Gültlinger J, Gauterin F, Brandau C, Schlittenhard J, Wies B. Investigations of Road Wear Caused by Studded Tires. Tire Sci Technol 2014;42(1):2-15.

[21] International Organization for Standardization. ISO/TS 13471-1: 2017. Acoustics - Temperature influence on tyre/road noise measurement - Part 
1: Correction for temperature when testing with the CPX method. Geneva, Switzerland: International Organization for Standardization; 2017.

[22] Wehrens R, Putter H, Buydens LMC. The bootstrap: a tutorial. Chemom Intell Lab Syst 2000;54(1):35-52.

[23] Sandberg U, Glaeser K-P. Effect of tyre wear on noise emission and rolling resistance. Inter-Noise; Shanghai, China: Chinese Academy of Sciences. Institute of Acoustics; 2008.

[24] European Parliament and Council. Regulation (EC) No 1222/2009: Labelling of tyres with respect to fuel efficiency and other essencial parameters. Off J Eur Communities 2009.

[25] Skov RSH, Sandberg U. NordTyre - Noise Reduction Potential in Nordic Countries by Introduction of EU Tyre Label. Chicago, IL, USA: Inter-Noise; 2018.
[26] Sandberg U. Calibrating the ISO 10844 test surfaces used for vehicle and tyre noise testing. Hong Kong: Inter-Noise; 2017.

[27] Sandberg U, Ejsmont J. Reference Road Surfaces for Use in Tire/Road Noise Measurements. Inter-Noise; Munich: Federal Republic of Germany; 1985.

[28] CEDR Call, CEDR Transnational Road Research Programme Call 2018: Noise and Nuisance. Conference of European Directors of Roads (CEDR); http://www. cedr.eu/.

[29] Directive 2002/49/EC of the European Parliament and of the Council. COMMISSION DIRECTIVE (EU) 2015/996 of 19 May 2015 establishing common noise assessment methods. Official Journal of the European Union, L1 168/1, 1.7.2015. 